\title{
Rare earth elements and neodymium isotopes in sedimentary organic matter
}

\author{
Nicolas Freslon ${ }^{a, b, ~ *, ~ G e r m a i n ~ B a y o n ~}{ }^{a}$, Samuel Toucanne ${ }^{a}$, Sylvain Bermell ${ }^{a}$, Claire Bollinger ${ }^{b, c}$, \\ Sandrine Chéron ${ }^{a}$, Joel Etoubleau ${ }^{a}$, Yoan Germain ${ }^{a}$, Alexis Khripounoff ${ }^{d}$, Emmanuel Ponzevera ${ }^{a}$, \\ Marie-Laure Rouget ${ }^{\mathrm{b}, \mathrm{c}}$
}

\author{
a IFREMER, Unité de Recherche Géosciences Marines, F-29280 Plouzané, France \\ ${ }^{\mathrm{b}}$ UEB, Université Européenne de Bretagne, F-35000 Rennes, France \\ c IUEM, Institut Universitaire Européen de la Mer, Université de Bretagne Occidentale, CNRS UMS 3113, IUEM, \\ F-29280 Plouzané, France \\ d IFREMER, Unité de Recherche Environnements Profonds, F-29280 Plouzané, France
}

\author{
*: Corresponding author : Nicolas Freslon, tel.: +00 33229008559 ; fax: 0033298224570 ; email address : \\ nicolas.freslon@ifremer.fr
}

\begin{abstract}
:
We report rare earth element (REE) and neodymium $(\mathrm{Nd})$ isotope data for the organic fraction of sediments collected from various depositional environments, i.e. rivers $(n=25)$, estuaries $(n=18)$, openocean settings $(n=15)$, and cold seeps $(n=12)$. Sedimentary Organic Matter (SOM) was extracted using a mixed hydrogen peroxide/nitric acid solution $\left(20 \%-\mathrm{H}_{2} \mathrm{O}_{2}-0.02 \mathrm{M}-\mathrm{HNO} \mathrm{N}_{3}\right)$, after removal of carbonate and oxy-hydroxide phases with dilute hydrochloric acid $(0.25 \mathrm{M}-\mathrm{HCl})$. A series of experimental tests indicate that extraction of sedimentary organic compounds using $\mathrm{H}_{2} \mathrm{O}_{2}$ may be complicated occasionally by partial dissolution of sulphide minerals and residual carbonates. However, this contamination is expected to be minor for REE because measured concentrations in $\mathrm{H}_{2} \mathrm{O}_{2}$ leachates are about two-orders of magnitude higher than in the above mentioned phases.
\end{abstract}

The mean REE concentrations determined in the $\mathrm{H}_{2} \mathrm{O}_{2}$ leachates for samples from rivers, estuaries, coastal seas and open-ocean settings yield relatively similar levels, with $\Sigma$ REE $=109 \pm 86$ ppm (mean $\pm s ; n=58)$. The organic fractions leached from cold seep sediments display even higher concentration levels $(285 \pm 150$ ppm; mean $\pm \mathrm{s}$; $n=12)$. The $\mathrm{H}_{2} \mathrm{O}_{2}$ leachates for most sediments exhibit remarkably similar shale-normalized REE patterns, all characterized by a mid-REE enrichment compared to the other REE. This suggests that the distribution of REE in leached sedimentary organic phases is controlled primarily by biogeochemical processes, rather than by the composition of the source from which they derive (e.g. pore, river or sea- water).

The $\mathrm{Nd}$ isotopic compositions for organic phases leached from river sediments are very similar to those for the corresponding detrital fractions. In contrast, the SOM extracted from marine sediments display $\varepsilon_{\mathrm{Nd}}$ values that typically range between the $\varepsilon_{\mathrm{Nd}}$ signatures for terrestrial organic matter (inferred from the analysis of the sedimentary detrital fractions) and marine organic matter (inferred from the 
analysis of local surface seawater). A notable exception is the case of organic matter (OM) fractions leached from cold seep sediment samples, which sometimes exhibit $\varepsilon_{N d}$ values markedly different from both terrigenous and surface seawater signatures. This suggests that a significant fraction of organic compounds in these sediments may be derived from chemosynthetic processes, recycling pore water REE characterized by a distinct isotopic composition.

Overall, our results confirm that organic matter probably plays an important role in the oceanic REE budget, through direct scavenging and remineralization within the water column. Both the high REE abundances and the shape of shale-normalized patterns for leached SOM also suggest that OM degradation in sub-surface marine sediments during early diagenesis could control, to a large extent, the distribution of REE in pore waters. Benthic fluxes of organic-bound REE could hence substantially contribute to the exchange processes between particulates and seawater that take place at ocean margins. Neodymium isotopes could provide useful information for tracing the origin (terrestrial versus marine) and geographical provenance of organic matter, with potential applications in paleoceanography. In particular, future studies should further investigate the potential of $\mathrm{Nd}$ isotopes in organic compounds preserved in sedimentary records for reconstructing past variations of surface ocean circulation.

Keywords : Organic matter ; Rare earth elements ; REE ; Neodymium isotopes ; $\varepsilon N d$; Sediment ; Boundary Exchange ; Paleoceanography

\section{Introduction}

\subsection{Organic matter in sediments}

Organic matter (OM) plays an important role in the biogeochemical and exchange processes between the atmosphere, hydrosphere and geosphere. In aquatic environments, OM is often composed of a complex mixture of natural biopolymers (e.g. lipids, sugars, proteins), geopolymers (e.g. humic substances) and bio-monomers related, or not, to microbial degradation (Killops and Killops, 2004, Lee et al., 2004, Meyers and Ishiwatari, 1993 and Wakeham and Lee, 1989). The organic compounds present in natural waters are generally derived from photosynthetic processes, with the exception of deep-sea extreme environments, such as submarine hydrothermal systems and methane seeps, where organic biomass can be produced by chemosynthesis. A significant fraction of particulate OM in seawater may also have a terrestrial origin, being delivered to the ocean via rivers or atmospheric inputs. In the ocean, particulate OM is biologically and/or chemically degraded as it settles through the water column. In fact, only a minor fraction (between 10 to $60 \%$ ) of the particulate OM produced in surface waters can reach the seafloor (Kappler et al., 2001). After deposition, 
another substantial fraction of OM may be remineralized in sub-surface sediments during early diagenetic processes (Froelich et al., 1979).

Various geochemical proxies have been used for determining the origin of $\mathrm{OM}$ in sediments. Conventional proxies include $\mathrm{C} / \mathrm{N}$ ratios and $\delta^{3} \mathrm{C}$ for discriminating between marine and terrestrial organic sources in sediments (Baudin et al., 2010; Hedges et al., 1997; Huon et al., 2002; Lamb et al., 2006). The ability of these proxies for tracing the origin of sedimentary organic phases is well established, but their use can be complicated by various factors, including diagenesis. In some cases, $\mathrm{C} / \mathrm{N}$ and $\delta^{3} \mathrm{C}$ data can also be difficult to interpret when dealing with complex mixtures of distinct marine and terrestrial organic sources. More recently, the emergence of molecular tracers (e.g. fatty acids, alkenones, alcohols) has provided new tools for characterizing OM in sediments (Herbert, 2001; Hopmans et al., 2004; Schouten et al., 2002; Treignier et al., 2006; Weijers et al., 2007). Novel approaches for determining the provenance of sedimentary organic matter (SOM) include lipid analyses, such as the BIT-index, which corresponds to the relative amount of marine versus continental lipids (branched and isoprenoid tetraethers) to sediments (Hopmans et al., 2004). Another approach has been the analysis of trace elements bound to OM (Tessier et al., 1979; Tribovillard et al., 2006), although the distribution of many of these elements (e.g. $\mathrm{Fe}, \mathrm{Mn}, \mathrm{Cu}, \mathrm{Cd}, \mathrm{V}$ ) can be controlled primarily by redox conditions, thereby making them inappropriate for tracing OM sources.

\subsection{Rare Earth Elements in the marine environment}

The rare earth elements (REE) comprise a particularly coherent group of elements with a preferred trivalent oxidation state, except for $\mathrm{Ce}$ and $\mathrm{Eu}$, which can also exist in the tetra- and di-valent oxidation states, respectively. Despite their intrinsic chemical coherence, the REE exhibit significant fractionation in the marine environment, which is due to systematic decreasing ionic radii with increasing atomic number. As a consequence, they can provide unique insights into biogeochemical processes in the ocean. The global REE budget in seawater is thought to be controlled by continental inputs, although the different gateways of REE to the ocean are not well constrained yet (Arsouze et al., 2009; Tachikawa et al., 2003). Previous studies of the oceanic chemistry of the REE (Bertram and Elderfield, 1993; Elderfield et al., 1990; Sholkovitz et al., 1994), modelling (Arsouze et al., 2009; Byrne and Kim, 1990; Lee and Byrne, 1992, 1993) and experimental work (Byrne and Kim, 1990; 
Koeppenkastrop and Decarlo, 1992, 1993) indicate that the marine abundance of REE can be regulated by scavenging processes involving principally Fe-Mn oxide coatings and OM on particles. To a large extent, the behaviour of dissolved REE in aquatic environments is controlled by the competitive binding of carbonate ions versus organic (humic acid) ligands (Censi et al., 2010; Marsac et al., 2011; Pourret et al., 2007a, b, c). Despite the potential importance of organic compounds in the marine REE geochemistry, the distribution of REE in SOM has been surprisingly overlooked so far.

Amongst the REE, neodymium is of particular interest because of one of its isotopes $\left({ }^{143} \mathrm{Nd}\right)$ is derived from the radioactive decay of ${ }^{147} \mathrm{Sm}$. Neodymium isotopic ratios $\left({ }^{143} \mathrm{Nd} /{ }^{144} \mathrm{Nd}\right)$ are usually expressed as $\varepsilon_{\mathrm{Nd}}$ values, which represent the deviation of ${ }^{143} \mathrm{Nd} /{ }^{144} \mathrm{Nd}$ to the CHUR (Chondritic Uniform Reservoir) reference value. In the marine environment, $\mathrm{Nd}$ isotopes combine unique properties, which make them powerful tracers of present and past ocean circulation (Frank, 2002). The Nd isotopic composition recorded by authigenic and biogenic phases faithfully replicates the signature of the seawater from which they have precipitated, and can be used to trace advection and mixing of past water masses within the ocean. Most of the paleoceanographic archives investigated so far with the $\varepsilon_{\mathrm{Nd}}$ proxy (i.e., Fe-Mn nodules/crusts and coatings, uncleaned foraminifera, fish teeth, corals) allow the reconstruction of past bottom water circulation patterns. Neodymium isotopes have also been applied to planktonic foraminifera to investigate past surface circulation (Burton and Vance, 2000; Vance and Burton, 1999; Vance et al., 2004), but this approach is complicated by post-depositional contamination related to the formation of $\mathrm{Fe}-\mathrm{Mn}$ oxyhydroxide coatings (Elmore et al., 2011; Tachikawa et al., 2013; Tachikawa et al., 2014). To date, the application of $\mathrm{Nd}$ isotopes to SOM, as a potential tracer for past surface circulation for example, has never been investigated.

\subsection{Objectives of this study}

In this study, the objective was first to develop a procedure allowing the determination of trace element abundances and Nd isotopic compositions in sedimentary organic phases. The extraction of organic fractions from sediments is typically achieved using a sequential leaching procedure, which aims at isolating organic phases from any biogenic (e.g. carbonates), authigenic (e.g. Fe-Mn oxy-hydroxides), and terrigenous phases (Tessier et al., 1979). Then, using our revised procedure, we measured REE and Nd isotopic compositions in 
organic phases leached from a series of samples collected from various sedimentary environments (rivers, estuaries, coastal margins, open-ocean, cold seeps). Finally, we briefly discuss on the factors controlling the incorporation of REE into organic compounds, and assess the utility of using $\mathrm{Nd}$ isotopes in sedimentary organic fractions for paleoenvironmental reconstructions.

\section{MATERIALS AND METHODS}

\subsection{Sample collection}

\subsubsection{Sediments}

The list/location of the sediments $(n=70)$ used for this study is given in Table 1 and Fig. 1. The samples were collected from surface sediments (or marine core-tops) from various regions in the world. They were organised in four different classes depending on their depositional environment. Sediments sampled in rivers were classified into two groups: 'Rivers' ( $\mathrm{n}=25)$ for sediments collected upstream from estuaries, and 'Estuaries' ( $\mathrm{n}=18)$, when any possible marine influence was suspected. Core-top sediments from Open-ocean settings were also used in the study ('Open-ocean'; $n=15)$. A few sediments $(n=12)$ recovered on continental margins in methane-seepage areas ('Cold seeps') were also investigated. In order to prevent any heterogeneity related to grain-size variations between samples, all bulk sediments were sieved, and only the $<63 \mu \mathrm{m}$ fraction was retained for analysis.

\subsubsection{Surface waters}

During the course of our study, we investigated whether the $\mathrm{Nd}$ isotopic signature of SOM from marine sediments could reflect that of overlying surface waters. For this purpose, we used the database for seawater $\mathrm{Nd}$ isotopic ratios compiled by Lacan et al., 2012. In addition, three surface seawater samples were analysed (Fig. 1; Table 1). This included a coastal surface seawater sample (Dellec-SW; Freslon et al., 2011) from Brittany (NW France), and two other surface seawater samples from the Gulf of Guinea (Congo and Gabon margins). These samples were processed and analysed using the procedure described in (Bayon et al., 2011a). 


\subsection{Reagents}

All chemical preparations described below were conducted in a Class 1000 (ISO 6) clean laboratory. Deionized water purified with a Milli-Q system (Millipore ${ }^{\circledR}$ ) at $18.2 \mathrm{M} \Omega$ (thereafter referred to as $\mathrm{MQ}-\mathrm{H}_{2} \mathrm{O}$ ) was used for material cleaning and acid dilutions. Polypropylene tubes, $0.2 \mu \mathrm{m}$ Teflon filters and disposable pipette tips were pre-cleaned thoroughly using diluted nitric acid solutions and $\mathrm{MQ}-\mathrm{H}_{2} \mathrm{O} . \mathrm{HNO}_{3}$ and $\mathrm{HCl}$ solutions (commercial grade, Merck) were twice-distilled using a sub-boiling system. Hydrogen peroxide $\mathrm{H}_{2} \mathrm{O}_{2}$ (Trace select, 30\%) from Fisher Scientific ${ }^{\circledR}$ (Loughborough, UK) and a thulium mono-elementary solution (custom grade, CGTM1-1, Inorganic Ventures Inc.) were also used.

\subsection{Experimental procedures}

\subsubsection{Method development}

Over the last decades, many of the sequential extraction procedures used for sediments have been derived from the protocol described in Tessier et al., 1979. The Tessier et al.'s leaching scheme involves the use of acetic acid (AA) and hydroxylamine hydrochloride (HH) solutions to extract carbonate and oxy-hydroxide fractions, respectively, prior to $\mathrm{OM}$ extraction with a mixed hydrogen peroxide $\left(\mathrm{H}_{2} \mathrm{O}_{2}\right)$ and dilute nitric acid solution (Gupta and Chen, 1975). More recently, this protocol was revisited in the light of novel paleoceanographic applications using radiogenic isotopes (Bayon et al., 2002; Gutjahr et al., 2007). The entire procedure was not used in our study because HH solutions have been suspected to release substantial amounts of trace elements bound to organic matter (Filgueiras et al., 2002). In addition, HH leaching may also lead occasionally to partial dissolution of detrital material in the case of volcanogenic sediments (Elmore et al., 2011; Wilson et al., 2013). Therefore, a series of chemical treatments were conducted to assess the impact of various carbonate/oxy-hydroxide leaching steps on the extraction of organic matter by mixed $\mathrm{H}_{2} \mathrm{O}_{2}$ - dilute nitric solution. These experiments were performed on two sediment samples: one sediment from the Murray River (Australia; \#7, Table 1), and one carbonate-rich (63\%wt $\mathrm{CaCO}_{3}$ ) marine sediment from the North Atlantic (\#56, Table 1). These experimental tests included the use of up-to-four $0.25 \mathrm{M}-\mathrm{HCl}$ leaching steps ( $45 \mathrm{~min}$ at $85^{\circ} \mathrm{C}$ on hotplate). As a reference, for comparison, the same samples were also treated using the protocol developed by Bayon et al. (2002), which ensures complete removal of carbonate and Fe-Mn oxy- 
hydroxide phases using 10\% AA and mixed 25\% AA - 1M-HH solutions. The efficiency of these chemical treatments was also assessed relative to more aggressive extraction schemes using stronger $\mathrm{HCl}$ solutions $\left(1 \mathrm{M}-\mathrm{HCl}\right.$ and $6 \mathrm{M}-\mathrm{HCl}$ during $4 \mathrm{~h}$ at $\left.85^{\circ} \mathrm{C}\right)$. Note that each of the leaching steps investigated during the course of this study were performed on separate bulk sediment samples.

\subsubsection{Recommended procedure}

The results of the experimental analyses will be presented in the Results section, but our final recommended procedure is described below. About 500 to $750 \mathrm{mg}$ of ground $<63 \mu \mathrm{m}$ sediment were placed in a $60 \mathrm{ml}$ Savillex ${ }^{\circledR}$ vial with $15 \mathrm{ml} 0.25 \mathrm{M}-\mathrm{HCl}$, and left on hotplate at $85^{\circ} \mathrm{C}$ during 45 minutes with regular agitation. After $15 \mathrm{~min}$ cooling, the solution was transferred into a pre-cleaned centrifuge tube, and centrifuged $3 \mathrm{~min}$ at $4000 \mathrm{rpm}$. The supernatant was discarded and the residue was washed with $5 \mathrm{ml} \mathrm{MQ-} \mathrm{H}_{2} \mathrm{O}$, and centrifuged again. The same leaching step with $0.25 \mathrm{M}-\mathrm{HCl}$ was repeated once more. After final centrifugation, the residue was dried overnight at $50^{\circ} \mathrm{C}$.

About $\sim 250 \mathrm{mg}$ of the residue left after the $0.25 \mathrm{M}-\mathrm{HCl}$ leaching step were weighed and placed into a $60 \mathrm{ml}$ Savillex ${ }^{\circledR}$ vial with $6 \mathrm{ml} 0.02 \mathrm{M}-\mathrm{HNO}_{3}$ and $10 \mathrm{ml}$ conc. $(30 \%) \mathrm{H}_{2} \mathrm{O}_{2}$, and with a known weight of Tm spike (15 to $45 \mathrm{ng} \mathrm{Tm}$ ) (see section 2.4.1). The vial (not closed to avoid any overpressure) was left overnight on an automatic shaker at room temperature. After

centrifugation $(3 \mathrm{~min}$ at $4000 \mathrm{rpm})$, the supernatant was transferred into a cleaned Savillex ${ }^{\circledR}$ vial. The resultant residue was rinsed with $\mathrm{MQ}-\mathrm{H}_{2} \mathrm{O}$, centrifuged, and the new supernatant was added to the previous one. The final residue was dried overnight, and weighted the next morning. The supernatants were filtered at $0.2 \mu \mathrm{m}$ to remove any particle, evaporated on hotplate at $80^{\circ} \mathrm{C}$, then dissolved in $8 \mathrm{ml}$ concentrated $\mathrm{HNO}_{3}(\sim 13.5 \mathrm{M})$. The new solution was left overnight on hotplate at $140^{\circ} \mathrm{C}$ in the closed vial. This step was used to destroy any possible complexes formed with organic matter. Finally, after evaporation, the organic phase was then dissolved in $4 \mathrm{ml} 4 \mathrm{M}-\mathrm{HCl}$ (referred to as mother solution) and stored in a precleaned polypropylene bottle.

\subsubsection{Digestion of the residual detrital fractions}

The final residue left after the $\mathrm{H}_{2} \mathrm{O}_{2}$ leaching step was also analysed in order to determine the REE abundance and $\mathrm{Nd}$ isotopic composition of the detrital or terrigenous 
material (composed mainly of clays and other silicate minerals). The detrital fractions were digested by alkaline fusion. Details on the procedure can be found in Bayon et al. (2009).

\subsection{Analytical techniques}

\subsubsection{REE abundances}

REE abundances in the organic fractions were determined using a $150 \mu 1$-aliquot of the final mother solution diluted in $10 \mathrm{ml} \mathrm{HNO}_{3} 2 \%(\mathrm{v} / \mathrm{v})$. The REE concentrations were measured with a sector field inductively coupled plasma mass spectrometry (SF-ICP-MS, Thermo Element-2) at the Pôle Spectrométrie Océan (Brest, France), using the Tm addition method. Details about this calculation method can be found elsewhere (Barrat et al., 1996; Bayon et al., 2009; Freslon et al., 2011). The REE were measured in low resolution mode, and polyatomic oxide and hydroxide interferences were corrected using oxide formation rates determined by analysing solutions of ultra-pure water, $\mathrm{Ba}+\mathrm{Ce}, \mathrm{Pr}+\mathrm{Nd}$ and $\mathrm{Sm}+\mathrm{Eu}+\mathrm{Gd}+\mathrm{Tb}$ at the beginning of the measurement cycle. The uncertainty on all measurements was better than $5 \%$.

\subsubsection{Neodymium isotopes}

About $1 \mathrm{ml}$ of the final mother solution was used for $\mathrm{Nd}$ isotopic measurements. The REE were isolated using common ion exchange chromatography, including a first ion exchange resin to isolate the lanthanides (AG-50W-X8, Bio-Rad) and a second one (Ln resin, Eichrom) to isolate $\mathrm{Nd}$ (Bayon et al., 2012). Nd isotopic ratios were determined with a multicollector ICP-MS (MC-ICP-MS, Thermo Neptune) at the Pôle Spectrométrie Océan. ${ }^{143} \mathrm{Nd} /{ }^{144} \mathrm{Nd}$ ratios were normalized to ${ }^{146} \mathrm{Nd} /{ }^{144} \mathrm{Nd}=0.7219$ and expressed as $\varepsilon_{\mathrm{Nd}}$. This notation corresponds to deviation from the Chondritic Uniform Reservoir (CHUR) in parts per 10,000, using $\left[{ }^{143} \mathrm{Nd} /{ }^{144} \mathrm{Nd}\right]_{\mathrm{CHUR}}=0.512638$ (Jacobsen and Wasserburg, 1980), and is defined by : $\varepsilon_{\mathrm{Nd}}$ $=\left(\left[\left({ }^{143} \mathrm{Nd} /{ }^{144} \mathrm{Nd}\right)_{\text {sample }} /\left({ }^{143} \mathrm{Nd} /{ }^{144} \mathrm{Nd}\right)_{\mathrm{CHUR}}\right]-1\right) * 10,000$. The reproducibility of our measurements was estimated using repeated analyses of the JNdi-1 standard (Tanaka et al., 2000) during the course of this study (8 different sessions over a 6-month period), giving ${ }^{143} \mathrm{Nd} /{ }^{144} \mathrm{Nd}=0.512095 \pm 0.000009$ (mean $\pm 2 \mathrm{~s}, \mathrm{n}=150$ ). The external reproducibility expressed in the $\varepsilon_{\mathrm{Nd}}$ notation was \pm 0.3 . 


\subsection{Total Organic Carbon (TOC)}

Two different aliquots of ground bulk sediment ( $<63 \mu \mathrm{m}$ fraction) were used to determine concentrations in Total Organic Carbon (TOC). Analyses were performed on a C\&S analyser LECO ${ }^{\circledR}$ CS-125. The first pre-weighed aliquot (about 30-70mg) served for direct determination of Total Carbon (TC) abundance (results not shown here). The other aliquot (between 30-90mg) was first leached with $4 \mathrm{M}-\mathrm{HNO}_{3}$ to remove carbonates, dried overnight at $50^{\circ} \mathrm{C}$, and analysed the next morning for determination of organic carbon. Note that while this method ensures complete removal of carbonates prior to analysis, it may also lead to minor partial dissolution of the less refractory organic compounds.

\section{RESULTS}

\subsection{Method validity}

\subsubsection{Extraction of carbonate and Fe-Mn oxy-hydroxide phases}

The fraction of total sediment (wt\%) and of selected elements (Ca, Fe, REE) extracted during our leaching experiments are presented in Table 2 and Figure 2. The application of a reference procedure (AA+HH; Bayon et al., 2002) for extracting both carbonate and oxyhydroxide phases in the North Atlantic (KN166-14 8 GGC) and Murray River sediment samples led to removal of about $86 \mathrm{wt} \%$ and $74 \mathrm{wt} \%$ of total calcium, respectively (Fig. 2a,b). Similar amounts of $\mathrm{Ca}$ were also dissolved using stronger acid solutions (1M-HCl and $6 \mathrm{M}-$ $\mathrm{HCl}$ ), indicating complete carbonate removal from the bulk sediments. For these two test samples, residual calcium was hence likely associated with detrital silicate-rich material. The investigation of the effect of weaker $0.25 \mathrm{M}-\mathrm{HCl}$ leach solutions showed that one single $0.25 \mathrm{M}-\mathrm{HCl}$ leaching step was clearly not enough to achieve full carbonate dissolution (less than $60 \mathrm{wt} \%$ of total calcium were dissolved in the two samples). In these samples, the residual (undissolved) carbonate fraction was removed subsequently during the $\mathrm{H}_{2} \mathrm{O}_{2}$ leaching step, as indicated by the high Ca recovery contents (wt\%) of the corresponding $\mathrm{H}_{2} \mathrm{O}_{2}$ leachates (Fig. 2c,d). In fact, one or two additional $0.25 \mathrm{M}-\mathrm{HCl}$ leaching steps were needed to ensure complete carbonate removal in the two test samples (Fig. 2a,b). River and marine sediments may also contain abundant iron (and manganese) oxyhydroxide phases present as coatings onto biogenic or detrital particles. Although Fe can be found in other sedimentary fractions (e.g. organic matter, sulphides and silicate minerals), it is used here to discuss about the efficiency of $0.25 \mathrm{M}-\mathrm{HCl}$ solutions for extracting Fe-Mn oxy-hydroxides from sediment 
samples. The amount of iron extracted from the North Atlantic and Murray River sediment samples using our reference procedure was about 12 and $8 \mathrm{wt} \%$, respectively. Leaching with two successive $0.25 \mathrm{M}-\mathrm{HCl}$ steps yielded very similar dissolved Fe recovery (i.e. $\sim 11 \%$ and $10 \%$, respectively). However, for the samples treated with additional successive $0.25 \mathrm{M}-\mathrm{HCl}$ leaching steps $\left(3^{\text {rd }}\right.$ and $\left.4^{\text {th }}\right)$ and stronger $\mathrm{HCl}$ solutions, the amounts of extracted Fe were clearly higher than those recovered using our reference protocol, indicating partial dissolution of detrital silicate-rich minerals. Importantly, iron is known to form complexes with organic matter, and the progressive decreasing contents of $\mathrm{H}_{2} \mathrm{O}_{2}$-extracted Fe following sequential leaching with increasing strength of $\mathrm{HCl}$ solutions also suggested that the use of strong $\mathrm{HCl}$ solutions (or even 3-to-4 successive $0.25 \mathrm{M}-\mathrm{HCl}$ leaching) could partially attack organic matter.

Based on the above experimental work, two leaching steps with $0.25 \mathrm{M}-\mathrm{HCl}$ appear to represent the best compromise for achieving 1) near quantitative removal of carbonate and $\mathrm{Fe}$ Mn oxyhydroxide phases, and 2) limited impact on sedimentary organic matter. The REE data obtained during the same series of experiments support similar conclusions. Indeed, the highest levels of REE measured in $\mathrm{H}_{2} \mathrm{O}_{2}$ leachates were those following leaching with only one $0.25 \mathrm{M}-\mathrm{HCl}$ step, suggesting that the fraction of REE associated with any undissolved carbonate and Fe-Mn oxyhydroxide phases was then further extracted by $\mathrm{H}_{2} \mathrm{O}_{2}$ solutions. After leaching twice the sediment with $0.25 \mathrm{M} \mathrm{HCl}$, however, we expect almost complete removal of REE bound to carbonate/oxide phases. In addition, similar to $\mathrm{Fe}$, the decreasing REE contents in $\mathrm{H}_{2} \mathrm{O}_{2}$ solutions following leaching with increasing strength of $\mathrm{HCl}$ solutions also suggested that strong $\mathrm{HCl}$ solutions could also release a fraction of REE bound to organic compounds. The procedure described above with two successive $0.25 \mathrm{M}-\mathrm{HCl}$ leaching steps hence also seems to represent the best compromise for the analysis of rare earth elements bound to organic matter.

\subsubsection{Organic matter extraction}

\section{$\underline{\text { 3.1.2.1. Effect of } \mathrm{H}_{2}} \underline{\mathrm{O}}_{2} \underline{\text { concentration on organic matter extraction }}$}

An organic-rich sediment sample from the Loire River $(\mathrm{TOC}=3.8 \% \mathrm{wt})$, previously cleared off any carbonate and oxy-hydroxide phases (using two $0.25 \mathrm{M}-\mathrm{HCl}$ leaching steps see above recommended procedure), was treated with mixed solutions of various $\mathrm{H}_{2} \mathrm{O}_{2}$ concentrations $(0.5 \%, 1 \%, 2.5 \%, 5 \%, 10 \%, 15 \%$, and $20 \% \mathrm{v} / \mathrm{v})$ and $\mathrm{HNO}_{3} 0.02 \mathrm{M}$. Note that 
$20 \% \mathrm{v} / \mathrm{v} \mathrm{H}_{2} \mathrm{O}_{2}$ is the concentration used by Tessier et al. (1979). The trace element data (Y, REE, Sr, Ba, Cr, Mn, Ni, Co, Cu, Zn, $\mathrm{Rb}, \mathrm{Zr}$ and $\mathrm{P}$ ) determined on the $\mathrm{H}_{2} \mathrm{O}_{2}$ leachates do not exhibit any significant variations for these elements (Table S1). Only the least concentrated $\mathrm{H}_{2} \mathrm{O}_{2}$ solutions (i.e. $0.5 \%$ and $1 \%$ ) appeared to extract less REE (34\%) and P (56\%). The differences observed for the other more concentrated $\mathrm{H}_{2} \mathrm{O}_{2}$ solutions were generally less than $10 \%$ RSD (i.e. of the same order of magnitude than analytical uncertainty), thus considered to be negligible. Based on these results, we decided to follow the same protocol used by Tessier et al. (1979) for $\mathrm{OM}$ extraction in all samples, i.e. using a $20 \%-\mathrm{H}_{2} \mathrm{O}_{2}+0.02 \mathrm{M}-\mathrm{HNO}_{3}$ mixed solution.

\subsubsection{Potential sources of REE contamination in leached organic fractions}

The TOC values are listed in Table 3. Sediments from 'Estuaries' and 'Rivers' were characterized by TOC contents $(3.0 \pm 1.9, \mathrm{n}=13$; and $3.2 \pm 1.8 ; \mathrm{n}=6)$, respectively higher than those from 'Cold seeps' and 'Open-ocean' sub-groups $(1.4 \pm 0.7, \mathrm{n}=12$; and $1.3 \pm 1.0, \mathrm{n}=9$, respectively). For both 'Rivers' and 'Estuaries', TOC contents were positively correlated with the amount of sample leached by $\mathrm{H}_{2} \mathrm{O}_{2}$ (referred to as leached organic matter (LOM) from hereafter and in Tables 3 and 4), exhibiting LOM/TOC ratios ranging between 2.0 and 4.6 (see Table 3). For comparison, the ratio between total organic matter and TOC in soils is generally assumed to be $\sim 1.8$ (i.e. the Van Bemmelen factor), although terrestrial and marine sediments often exhibit much higher ratios (e.g. Bianchi et al., 2008; Burone et al., 2003).

In our study, a few samples (i.e. \#15, \#28, \#34, \#38) were characterized by higher LOM/TOC ratios (between 7 and 16), indicating a possible contribution from residual carbonate/oxide phases, but also, most likely, from sulphides (e.g. pyrite). This latter mineral is known to be also leached with $\mathrm{H}_{2} \mathrm{O}_{2}$ solutions (Tessier et al., 1979). In our study, the presence of pyrite in the above samples characterized by high LOM/TOC ratios was clearly confirmed by XRD analyses (data not shown here, but available upon request). The 'Cold seeps' sediments analysed during the course of this study (i.e. which typically correspond to pyrite-bearing anoxic sediments) were also characterized by high LOM/TOC ratios (mean = 6.5), further confirming pyrite extraction during the $\mathrm{H}_{2} \mathrm{O}_{2}$ leaching step. Importantly, however, pyrite is generally relatively depleted in REE ( $\mathrm{REE}<3 \mathrm{ppm}$; Zhou et al., 2011), so that the pyrite-bound REE fraction extracted during $\mathrm{H}_{2} \mathrm{O}_{2}$ leaching is expected to represent only a minor component of the total leached REE fraction $(<5 \%)$. In addition, a few samples 
from the 'Open-ocean' class (\#44, \#46, \#48, \#49 and \#51) were also characterized by relatively high LOM/TOC ratios (>5), which here were related to contamination from residual carbonate/oxide phases, as inferred from the high $\mathrm{Ca}$ counts measured in the corresponding $\mathrm{H}_{2} \mathrm{O}_{2}$ leachates relative to the other studied samples. Similar to pyrite, biogenic carbonates are generally also depleted in REE ( $\mathrm{REE}<10$ ppm; Nothdurft et al., 2004; Sholkovitz and Shen, 1995; Webb and Kamber, 2000). As a consequence, minor to moderate carbonate contamination during $\mathrm{H}_{2} \mathrm{O}_{2}$ leaching is expected to mainly act as a dilution factor for the REE contents determined in $\mathrm{H}_{2} \mathrm{O}_{2}$ leachates. In contrast, marine Fe-Mn oxide precipitates are typically enriched in REE, and hence would represent a potentially non-negligible source of contamination in our $\mathrm{H}_{2} \mathrm{O}_{2}$ leachates. However, the REE abundances and shale-normalized patterns of the $\mathrm{H}_{2} \mathrm{O}_{2}$ fractions from these samples characterized by high LOM/TOC ratios are indistinguishable from those from all other studied samples (Table 3). We also do not observe any correlation between LOM/TOC ratios and Ce-anomaly, which would indicate the presence of authigenic Mn-oxides in the $\mathrm{H}_{2} \mathrm{O}_{2}$ leachates. Taken together, all the above consideration hence would provide evidence that the potential contamination issues mentioned above probably only have minor effect on the distribution of REE and Nd isotopic compositions in our leached organic fractions. Note however that this may not be the case for other trace elements (e.g. $\mathrm{Fe}, \mathrm{Pb}$ ), which hence would require further investigation.

\subsubsection{Certified Reference Materials}

The reproducibility of our method was assessed using two certified reference materials (CRM) provided by the United States Geological Survey (USGS): MAG-1 (a marine sediment from the Gulf of Maine, NW Atlantic Ocean) and SGR-1 (a shale from the Green River Formation in the Rocky Mountains, USA). Ten replicates were analysed for MAG-1 and 6 for SGR-1 (Table 4). The amount of carbonate/oxide-free material extracted by $\mathrm{H}_{2} \mathrm{O}_{2}$ was less reproducible for MAG-1 (17\% RSD) than for SGR-1 (10\% RSD), perhaps due to the difficulty in quantitatively removing the biogenic fraction from a carbonate-rich marine sediment (see above discussion). The reproducibility for measured REE abundances was generally lower than 21\%RSD and 16\%RSD for MAG-1 and SGR-1, respectively. However, only negligible variations were observed on the shale-normalized REE patterns. The relative standard deviations (RSD) determined for $[\mathrm{La} / \mathrm{Yb}]_{\mathrm{N}}$ were about $7 \%$ and $2 \%$ (for MAG-1 and SGR-1, respectively); $[\mathrm{Gd} / \mathrm{Yb}]_{\mathrm{N}}(5 \%$ and $6 \%) ;[\mathrm{Sm} / \mathrm{Nd}]_{\mathrm{N}}(1 \%$ and $2 \%)$. Moreover, RSD for the Ce anomaly (defined by $2 * \mathrm{Ce}_{\mathrm{N}} /\left[\mathrm{La}_{\mathrm{N}}+\mathrm{Pr}_{\mathrm{N}}\right]$ ) was about $2 \%$ for both MAG-1 and SGR-1. 
Finally, the determination of $\mathrm{Nd}$ isotopic ratios on three replicates of each CRM gave average values with uncertainty lower than the analytical external reproducibility for $\mathrm{Nd}$ isotopic measurements on MC-ICP-MS (0.3 $\varepsilon$-units).

\subsection{Rare earth elements bound to sedimentary organic matter}

The distributions of REE in the seventy $\mathrm{H}_{2} \mathrm{O}_{2}$ leachates analysed in this study are listed in Table 3. Given concentrations correspond to the amount of leached REE over the total mass of carbonate and oxide-free sample extracted using $\mathrm{H}_{2} \mathrm{O}_{2}$ (expressed in ppm). The first notable feature was the high concentration level of REE bound to sedimentary organic matter. As an example, the organic fractions extracted from 'Rivers', 'Estuaries' and 'Openocean' samples exhibited concentrations in the range of $\sim 21 \pm 15 \mathrm{ppm}$ for $\mathrm{Nd}$, while 'Cold seeps' samples displayed even higher concentration levels $(55 \pm 30 \mathrm{ppm}$ for $\mathrm{Nd})$. The REE abundances were normalized to Post Achaean Australian Shale (PAAS; Taylor and McLennan, 1985) and classified by sedimentary depositional environment (Fig. 3). For all environments, sedimentary organic matter displayed remarkably similar REE patterns, characterized by medium-REE (from $\mathrm{Sm}$ to $\mathrm{Tb}$; thereafter noted as MREE) enrichments relative to light-REE (LREE, La-Nd) and heavy-REE (HREE, Tb-Yb). Our results are in agreement for both REE abundances (e.g. [Nd] between 14 and 300 ppm) and the shape of shale-normalized patterns (MREE enrichments) with published data for Cambrian-age organic matter (humic compounds; Felitsyn and Morad, 2002). Amongst all the studied samples, only three $\mathrm{H}_{2} \mathrm{O}_{2}$ leachates exhibited a different shale-normalized REE pattern. Those latter samples (\#13,\#14, \#18) were collected from the same granitic massif (Brittany, Western France). Concerning the redox-sensitive element cerium, it has to be noted that no (or small) negative Ce-anomalies were observed for sedimentary organic matter extracted from 'Rivers' $\left(\mathrm{Ce} / \mathrm{Ce}^{*}=1.07 \pm 0.22\right.$; average $\left.\pm \mathrm{s}\right)$ and 'Estuaries' $(0.94 \pm 0.06)$, while 'Openocean' $(1.41 \pm 0.53)$ and, to a lesser extent, 'Cold seeps' $(1.18 \pm 0.30)$ samples were characterized by positive anomalies.

\subsection{Neodymium isotopes}

\subsubsection{Neodymium isotopes bound to organic matter}

The Nd isotopic compositions $(\varepsilon N d)$ of SOM for all samples range from $~-27.0$ to +4.0. The less radiogenic values were obtained on samples recovered from rivers draining the 
old cratonic areas of Scandinavia $(\varepsilon N d=-23.3$ and -19.7 for Kiiminkijoki, \#16, and Kymijoki, \#17, rivers, respectively) and Amazonia (-27.0 for Rio Aro, \#19). The most radiogenic values were measured on organic matter extracted from volcanogenic sediments of the Reunion Island $(\varepsilon \mathrm{Nd}=+4.0, \# 22, \# 23)$.

\subsubsection{Neodymium isotopes in detrital fractions}

The residual fraction of sediments left after sequential leaching of carbonates, Fe-Mn oxy-hydroxides and organic matter (typically referred to as terrigenous or detrital fraction) is mainly composed of clay and other silicate minerals. Over the last two decades, this sediment fraction has been increasingly used to discuss sediment provenance and/or weathering processes (Bayon et al., 2003; Goldstein and Hemming, 2003; Grousset et al., 1988); however, that way of interpretation is not discussed in this paper. Here, the $\mathrm{Nd}$ isotopic compositions were only determined for comparison with organic matter $\varepsilon \mathrm{Nd}$ signatures. Results are presented in Table 3. Similar to the organic fractions, the detrital $\varepsilon N d$ ranged between -28.7 (\#19) and +3.9 (\#23).

\subsubsection{Neodymium isotopes in seawater samples}

The three coastal seawaters analysed in this study to complete the database provided by Lacan et al., 2012 gave the following results: Dellec-SW $(\varepsilon N d=-8.2)$; Congo margin $(\varepsilon N d$ $=-15.4)$; and Gabon margin $(\varepsilon N d=-14.7)$.

\section{DISCUSSION}

\subsection{Use of Nd isotopes for provenance studies of sedimentary organic matter}

\subsubsection{Characterization of continental sedimentary organic matter}

It is generally assumed that chemical alteration on continents does not fractionate $\mathrm{Nd}$ isotopes, i.e. that the weathering products of any given rock (dissolved loads, clays and suspended particles, sands) display an uniform Nd isotopic signature (Goldstein and Jacobsen, 1987, 1988a; Grousset et al., 1988; Rickli et al., 2010). Considering that terrestrial organic compounds incorporate dissolved $\mathrm{Nd}$ released from rock weathering, continental SOM preserved in soils or in river sediments should display in theory a similar $\varepsilon N d$ signature too. 
This is nicely shown when comparing the $\mathrm{Nd}$ isotopic compositions of SOM extracted from 'Rivers' sediments (noted $\varepsilon N d{ }_{\text {OM}}$ ) with their corresponding detrital $\varepsilon N d$ values ( $\varepsilon N d$ Terr.) (cf. Fig. 4). Apart from a few exceptions, the observed variations between those two sediment fractions are generally within $1 \varepsilon N d$ unit. The difference between $\varepsilon N d$ values for SOM and corresponding detrital fractions are greater for the following river samples: Rio Aro (\#19; 1.7 عNd-unit), Volga (\#12; 2.7), Orne (\#8; 1.9), Murray (\#7; 2.9) and Amu-Daria (\#1; 3.0). A few rare cases of $\mathrm{Nd}$ isotopic fractionation in silicate weathering products have been reported previously in specific glaciated environments (Ohlander et al., 2000; Andersson et al., 2001), but which obviously could not apply here in the context of these river basins. Instead, the observed variations most likely reflect the fact that those rivers drain contrasted geological units within their watershed, thereby possibly leading to distinct sources of organic versus terrigenous material in the sedimentary load delivered to the oceans (Milliman and Farnsworth, 2011). However, the overall good agreement between $\varepsilon \mathrm{Nd}$ OM and $\varepsilon \mathrm{Nd}$ Terr. for the twenty other studied river samples suggests that, to a first approximation, continental SOM generally displays $\mathrm{Nd}$ isotopic compositions similar to the associated detrital material.

\subsubsection{Differentiation between continental, marine and chemosynthetic organic matter}

In 'Estuaries' sediments, the differences measured between organic matter and detrital $\varepsilon N d$ signatures are generally greater than for river sediments (see above; Fig. 4). Fourteen out of the 18 estuary sediment samples analysed here exhibit differences ranging from 1.2 to 7 $\varepsilon N d$-units. Estuaries are generally the location of intense marine productivity. As a consequence, organic matter encountered in these depositional environments is expected to be composed of a mixture of continental and marine organic compounds. This is clearly shown with the sample from the Elorn estuary (Brittany, France), which exhibits an organic signature $(\# 29 ; \varepsilon N d$ oM $=-9.0)$ falling between $\varepsilon N d$ values for local surface waters (-8.2; Dellec-SW) and corresponding detrital sediments $(\varepsilon N d$ Terr. $=-15.6)$. The same observation can also be made for the only other estuary sample (Yangtze River \#43; $\varepsilon N d$ OM $=-9.7$ and $\varepsilon N d$ Terr. $=-$ 12.0) for which local coastal seawater $\varepsilon N d$ was available (-6.7; Tazoe et al., 2011).

The Nd isotopic composition of organic matter extracted from 'Open-ocean' sediments can also be compared with $\varepsilon N d$ values for the corresponding detrital fraction and the nearest surface seawater in order to determine its provenance (Fig. 5a). For example, a few samples from the China Sea (\#48-49) and the Eastern Mediterranean (\#55) display SOM $\varepsilon \mathrm{Nd}$ values identical to local surface seawater values, but distinct from their associated 
terrigenous fractions. In this case, this implies that the sedimentary organic matter fraction extracted from these samples has a marine origin. In contrast, a group of samples from the Bermuda Rise (\#45), Hawaiian Arch (\#52), Japan Sea (\#53-54), North Atlantic (\#56), Norwegian Sea (\#57) and Reunion Island area (\#58) is characterized by near identical organic and detrital $\varepsilon N d$ signatures that depart significantly from the local surface seawater value. While partial dissolution of easily dissolvable volcanogenic particles could possibly account, at least to some extent, for some of these detrital signatures, these data most likely indicate a continental provenance for SOM. Alternatively, as for the Blake Ridge sample (\#47), the $\mathrm{Nd}$ isotopic composition of extracted organic phases can also fall between the marine and detrital signatures, thereby suggesting a mixed provenance. Overall, while the $\mathrm{Nd}$ isotopic composition of any given SOM can point either towards seawater and/or a continental origin, our data indicate that it always falls between $\varepsilon N d$ values for the detrital and marine endmembers.

One particular exception arises however from a few sediment samples recovered from 'Cold seeps' in the Eastern Mediterranean Sea (\#64 to \#70). In contrast with all other studied samples, the organic fraction extracted from these sediments display $\mathrm{Nd}$ isotopic compositions more radiogenic (higher) than the range of corresponding detrital and marine $\varepsilon N d$ values (Fig. 5b). In cold seep settings, a significant fraction of sedimentary organic matter may be derived from chemosynthetic organisms living in these anoxic environments (Omoregie et al., 2008; Sibuet and Olu, 1998). Pore waters in fluid seepage areas are typically enriched in REE (Bayon et al., 2011b; Himmler et al., 2013). Dissolved REE in marine sediment pore waters are released during early diagenetic processes, related mainly to mineralization of buried organic matter and/or reduction of Fe-Mn oxyhydroxide phases (Haley et al., 2004; Soyol-Erdene and Huh, 2013). Advection processes at cold seeps may also lead to the presence of much deeper gas-rich fluids in sub-surface sediments. For these reasons, the $\mathrm{Nd}$ isotopic composition of pore waters (which is presumably further preserved in seafloor chemosynthetic organisms) may not necessarily reflect that of overlying surface waters and/or associated terrigenous sediments, thereby possibly explaining the anomalously high $\varepsilon N d$ values in the organic fraction extracted from our Eastern Mediterranean seep sediments.

\subsubsection{Applicability and potential limitations of Nd isotopes in sedimentary organic fractions}


With the exception of those sediments from methane seeps, the observation that the $\mathrm{Nd}$ isotopic composition of organic compounds extracted from marine sediments always falls between $\varepsilon N d$ values for the detrital and marine end-members suggests that this approach could be used for determining the provenance of sedimentary organic matter, and hence for possible future applications to paleo-environmental studies. For example, the use of $\mathrm{Nd}$ isotopes in SOM from sediment cores recovered from deep-sea fans at margins could provide qualitative information about variations on riverine paleo-discharges. In addition, SOM preserved in sedimentary records from open-ocean settings could be used to discuss about variations in past sea surface circulation patterns.

In such studies, one important requirement prior to using $\mathrm{Nd}$ isotopes in organic compounds as paleoceanographic tracers would be first, however, to assess whether the organic fraction extracted from core-top sediments at any given site display a sea surface $\AA_{\mathrm{Nd}}$ signature. Another limitation would also concern those specific cases where both surface water and terrigenous sediments display similar $\mathrm{Nd}$ isotopic signatures. In our study, this is clearly the case for the Gulf of Guinea, at the Congo and Niger Delta margins, where both seawater and detrital sediments display a very small range of \&vd values (Table 3). Because intense exchange processes are known to take place at ocean margins between seawater and particulates/sediments (e.g. Lacan and Jeandel, 2005; Tachikawa et al., 1999), we anticipate that this could also be the case at many other locations worldwide. In such cases, the \&rdproxy would be of limited use for tracing the source of sedimentary organic compounds. Finally, at this stage, it is unclear whether $\mathrm{Nd}$ isotopes could be used to provide quantitative constraints on the relative proportion of continental versus marine organic matter in sediments. While our results suggest that both continental and marine organic matter display_similar $\mathrm{Nd}$ concentrations (i.e. $21 \pm 15 \mathrm{ppm}$ ), further studies would be needed to determine whether these values can be taken as reliable end-member concentrations for calculating relative abundances of marine versus terrestrial organic fraction.

\subsection{Shale-normalized REE patterns of sedimentary organic matter}

\subsubsection{Importance of organic matter on REE scavenging}

Average shale-normalized REE patterns for sedimentary organic matter are presented in Fig. 6 (using the REE concentrations reported in Table 3), together with typical patterns for 
natural waters (seawater, river water, pore waters) and biogenic/authigenic marine phases (carbonates, Fe-Mn oxy-hydroxides). With the exception of acidic $(\mathrm{pH}<7)$ rivers, which are generally characterized by a small MREE enrichment relative to the LREE and HREE (Elderfield et al., 1990), the distribution of dissolved REE $(<0.45$ or $0.22 \mu \mathrm{m})$ in rivers and seawater usually indicates a progressive enrichment from the MREE to the HREE enrichments (Elderfield and Greaves, 1982; Elderfield et al., 1988). Dissolved lanthanides concentrations are about 10 times higher in rivers than in coastal seawater or open-ocean waters. To some extent, this reflects intense scavenging of REE in estuarine environments (about 90\%), that is usually explained by adsorption onto suspended particles and/or complexation with Fe-Mn oxy-hydroxides (Sholkovitz and Szymczak, 2000). Numerous phases (e.g. lithogenic particles, carbonates, oxides) can influence REE scavenging depending on the environment and local physico-chemical conditions (Davranche et al., 2004; Elderfield et al., 1990; Pourret et al., 2007c). The potential role of organic matter in scavenging dissolved REE via precipitation, complexation and/or adsorption remains poorly known however. Despite this uncertainty, several studies have shown that organic colloids could dominate REE retention in aqueous environments (Elderfield et al., 1990; Gaillardet et al., 1997; Sholkovitz, 1992; Stolpe et al., 2013). This is suggested by the positive correlation between dissolved REE and organic carbon (DOC) contents in river waters (Xu and Han, 2009). Interestingly, organic-rich colloidal phases reported in the above mentioned studies exhibit shale-normalized MREE enrichments similar to those determined in our SOM fractions, adding further support to the view that organic compounds may dominate REE complexation in natural waters.

Another argument for substantial REE scavenging by organic matter comes from the Ce anomalies measured in our SOM fractions. Negative Ce anomalies are commonly observed in natural waters (seawater, river water and groundwater; Elderfield et al., 1990), while positive $\mathrm{Ce}$ anomalies have only been reported in highly alkaline lake waters: $\mathrm{pH}>9$ (Moller and Bau, 1993). The strong negative Ce anomaly typical of seawater is usually explained by preferential scavenging of tetravalent cerium $\left(\mathrm{Ce}^{4+}\right)$ by $\mathrm{Fe}-\mathrm{Mn}$ oxy-hydroxides, which, in contrast, can display positive anomalies (Elderfield and Greaves, 1981; Ohta and Kawabe, 2001). In addition to Fe-Mn oxyhydroxide phases, humic substances have also been shown to preferentially take up $\mathrm{Ce}^{4+}$ from the dissolved pool, leading to positive anomalies in the organic fraction (Pourret et al., 2008). This observation is in full agreement with our 
results, which show that organic matter extracted from marine sediments often displays positive $\mathrm{Ce}$ anomalies. Although additional studies would be required to further investigate the role of organic matter in biogeochemical REE cycling, our results hence also suggest that organic compounds act as important REE scavenging phases in aquatic environments.

\subsubsection{Importance of organic matter to pore water and seawater REE cycling}

In marine sediments, pore waters generally display REE concentrations that are 1 or 2 orders of magnitude higher than in seawater, due to substantial REE release during early diagenetic processes. Dissolved REE in oxic sediments exhibit HREE enrichments relative to the other REE generally similar to seawater REE distribution patterns (Haley et al., 2004). In contrast, under suboxic and anoxic conditions, pore waters acquire a typical MREE 'bulge' shape pattern and lose the negative Ce anomaly typical of overlying bottom waters. The acquisition of this specific REE pattern has been interpreted as the result of Fe-Mn oxyhydroxide reduction in sediments (Haley et al., 2004; Kim et al., 2012). However, our results show that sedimentary organic matter also exhibits very similar MREE enrichments, together with no or small positive Ce anomaly. This suggests that organic matter degradation during early diagenetic processes could also control, to a greater extent than previously thought may be, the distribution of REE in suboxic/anoxic pore waters.

Overall, REE in marine sedimentary organic matter appear to about 10 times less concentrated than in deep-sea Fe-Mn nodules, but enriched by a factor of 10 to 100 compared to biogenic carbonates (see Fig. 6 and Table 5). Clearly, this relatively high level of concentrations suggest that organic matter cycling in the ocean probably plays an important role in the marine REE budget, as already proposed in earlier studies (Morgan et al., 2012; Pourret et al., 2008). Most likely, remineralization of continental or marine particulate organic matter in highly productive areas, or in sediments during early diagenetic processes, is expected to cause substantial release of dissolved REE in the marine environment. Although dissolved REE can be incorporated into organic matter in surface waters, only a small fraction actually reaches the sediment floor. But an additional fraction of particulate OM can also be further degraded in marine sediments during diagenetic processes, possibly releasing dissolved REE to bottom waters via benthic fluxes. While all the above processes are unlikely to play a dominant role in low-productivity oceanic regions, a substantial release of organic- 
bound dissolved $\mathrm{Nd}$ with a distinctive surface water isotopic signature is expected to occur along the entire water column in highly-productive areas, such as continental margins. Presumably, the recycling of surface waters REE via organic matter remineralization processes could play a role in the exchange processes between seawater and sediments that take place at ocean margins (e.g. boundary exchange). Thus, further consideration should attempt to investigate more closely the relationships between the marine organic matter cycle and the behaviour of REE in the ocean.

\section{CONCLUSIONS}

The results of this study suggest that further consideration should be taken into account about the role of organic matter in REE biogeochemical cycling, especially on its importance to the marine REE budget. Our data for $\mathrm{H}_{2} \mathrm{O}_{2}$ leachates show that the proportion of REE bound to sedimentary organic matter is not negligible ( $\mathrm{REE}=109 \pm 86 \mathrm{ppm}$, which corresponds to about $1.0 \pm 0.7 \mathrm{mg}$ per gram of TOC). Our data suggest that organic matter may be involved in the development of the typical negative $\mathrm{Ce}$ anomaly in seawater, and that remineralization of organic compounds in marine sediments could explain, at least partly, the distribution of REE in pore waters. The organic matter cycle appears to be closely linked with REE, but its impact is probably still underestimated. Further research work should focus on the interactions between suspended particles, colloidal phases and dissolved organic matter to provide further constraints about the impact of organic matter in the REE biogeochemical cycling.

In addition, we show that terrestrial organic matter displays the same $\mathrm{Nd}$ isotopic composition than weathering products of continental rocks, while marine organic compounds may record the $\varepsilon N d$ signature of surface waters. This implies that the $\mathrm{Nd}$ isotopic composition of organic matter preserved in marine sediments is generally controlled by the relative proportion between terrestrial versus marine organic material. In the future, the application of $\mathrm{Nd}$ isotopes to sedimentary OM could represent a good alternative for organic matter provenance studies. Additional studies would be needed to investigate whether organic fractions leached from sediments may be used for reconstructing the evolution of past surface water masses. In parallel, dedicated studies should investigate the extent to which exchange processes taking place in the water column, at the seafloor, or after sediment burial, could possibly affect REE 
distribution in sedimentary organic fractions and shift their $\mathrm{Nd}$ isotopic compositions towards bottom water signatures.

\section{ACKNOWLEDGEMENTS}

This work was sponsored by the French National Research Agency (ANR), via the ECO-MIST project (2010 JCJC 609 01). The authors are particularly grateful for help and support from all sample suppliers, without forgetting friends and families, which allowed us to acquire a large collection of samples for this study: Adeaga O., Bayon J., Bigler C., Bordalo A., Brunaud C., Busschers F., Calvès G., Cohen K., Elmore A., Elverhoi A., Groengroeft A., Haynes D., Hoogendoorn B., Jorry S., Kowalewska G., Leroy S., Lopez L., Lunkka J.P., Matoshko A., Mazuel A., Mendes I., Patzold J., Piotrowski A., Prego R., Rinterknetch V., Rodriguez-Rodriguez L., Saito Y., Shevchenko V., Toucanne D., Vaikutiene G., Vallius H., Vis G.J., Vitalis Z., Wheeler A., Winter C. Are also thanked Hélène Ondréas, Anne-Sophie Alix and Martin Guillou (IFREMER) for their help on our database and GIS, and also François Lacan LEGOS) for providing us with his global database for seawater $\mathrm{Nd}$ isotopes. This work would not have been possible without the interest and patience of people at the Pôle Spectrométrie Océan (PSO; Brest) and of NF's PhD supervisors (G. Jouet, G. Lericolais, and G. Menot).

\section{REFERENCES}

Akagi, T., Hashimoto, Y., Fu, F.F., Tsuno, H., Tao, H., Nakano, Y., 2004. Variation of the distribution coefficients of rare earth elements in modern coral-lattices: Species and site dependencies. Geochimica Et Cosmochimica Acta 68, 2265-2273.

Amakawa, H., Alibo, D.S., Nozaki, Y., 2000. Nd isotopic composition and REE pattern in the surface waters of the eastern Indian Ocean and its adjacent seas. Geochimica Et Cosmochimica Acta 64, 1715-1727.

Andersson, P.S., Dahlqvist, R., Ingrid, J. Gustafsson, O., 2001. The isotopic composition of $\mathrm{Nd}$ in a boreal river: A reflection of selective weathering and colloidal transport. Geochimica Et Cosmochimica Acta 65, 521-527.

Arsouze, T., Dutay, J.C., Lacan, F., Jeandel, C., 2009. Reconstructing the Nd oceanic cycle using a coupled dynamical - biogeochemical model. Biogeosciences 6, 2829-2846. 
Barrat, J.A., Keller, F., Amosse, J., Taylor, R.N., Nesbitt, R.W., Hirata, T., 1996. Determination of rare earth elements in sixteen silicate reference samples by ICP-MS after Tm addition and ion exchange separation. Geostandards Newsletter 20, 133-139.

Baudin, F., Disnar, J.-R., Martinez, P., Dennielou, B., 2010. Distribution of the organic matter in the channel-levees systems of the Congo mud-rich deep-sea fan (West Africa). Implication for deep offshore petroleum source rocks and global carbon cycle. Marine and Petroleum Geology 27, 995-1010.

Bayon, G., Barrat, J.A., Etoubleau, J., Benoit, M., Bollinger, C., Revillon, S., 2009. Determination of Rare Earth Elements, Sc, Y, Zr, Ba, Hf and Th in Geological Samples by ICP-MS after Tm Addition and Alkaline Fusion. Geostandards and Geoanalytical Research 33, 51-62.

Bayon, G., Birot, D., Bollinger, C., Barrat, J.A., 2011a. Multi-Element Determination of Trace Elements in Natural Water Reference Materials by ICP-SFMS after Tm Addition and Iron Co-precipitation. Geostandards and Geoanalytical Research 35, 145-153.

Bayon, G., Birot, D., Ruffine, L., Caprais, J.C., Ponzevera, E., Bollinger, C., Donval, J.P., Charlou, J.L., Voisset, M., Grimaud, S., 2011b. Evidence for intense REE scavenging at cold seeps from the Niger Delta margin. Earth and Planetary Science Letters 312, 443-452.

Bayon, G., Dennielou, B., Etoubleau, J., Ponzevera, E., Toucanne, S., Bermell, S., 2012. Intensifying Weathering and Land Use in Iron Age Central Africa. Science 335, 12191222.

Bayon, G., German, C.R., Boella, R.M., Milton, J.A., Taylor, R.N., Nesbitt, R.W., 2002. An improved method for extracting marine sediment fractions and its application to $\mathrm{Sr}$ and Nd isotopic analysis. Chemical Geology 187, 179-199.

Bayon, G., German, C.R., Burton, K.W., Nesbitt, R.W., Rogers, N., 2004. Sedimentary FeMn oxyhydroxides as paleoceanographic archives and the role of aeolian flux in regulating oceanic dissolved REE. Earth and Planetary Science Letters 224, 477-492.

Bayon, G., German, C.R., Nesbitt, R.W., Bertrand, P., Schneider, R.R., 2003. Increased input of circumpolar deep water-borne detritus to the glacial SE Atlantic Ocean. Geochemistry, Geophysics, Geosystems 4, 1025.

Bertram, C.J., Elderfield, H., 1993. The geochemical balance of the rare earth elements and neodymium isotopes in the oceans. Geochimica Et Cosmochimica Acta 57, 19571986.

Bianchi, S.R., Miyazawa, M., de Oliveira, E.L., Pavan, M.A., 2008. Relationship between the mass of organic matter and carbon in soil. Brazilian Archives of Biology and Technology 51, 253-269.

Burone, L., Muniz, P., Pires-Vanin, A.M.S., Rodrigues, M., 2003. Spatial distribution of organic matter in the surface sediments of Ubatuba Bay (Southeastern Brazil). Anais da Academia Brasileira de Ciencas 75, 77-90. 
Burton, K.W., Vance, D., 2000. Glacial-interglacial variations in the neodymium isotope composition of seawater in the Bay of Bengal recorded by planktonic foraminifera. Earth and Planetary Science Letters 176, 425-441.

Byrne, R.H., Kim, K.H., 1990. Rare earth element scavenging in seawater. Geochimica Et Cosmochimica Acta 54, 2645-2656.

Censi, P., Zuddas, P., Randazzo, L.A., Saiano, F., Mazzola, S., Arico, P., Cuttitta, A., Punturo, R., 2010. Influence of dissolved organic matter on rare earth elements and yttrium distributions in coastal waters. Chemistry and Ecology 26, 123-135.

Charbonnier, G., Puceat, E., Bayon, G., Desmares, D., Dera, G., Durlet, C., Deconinck, J.-F., Amedro, F., Gourlan, A.T., Pellenard, P., Bomou, B., 2012. Reconstruction of the Nd isotope composition of seawater on epicontinental seas: Testing the potential of Fe-Mn oxyhydroxide coatings on foraminifera tests for deep-time investigations. Geochimica Et Cosmochimica Acta 99, 39-56.

Davranche, M., Pourret, O., Gruau, G., Dia, A., 2004. Impact of humate complexation on the adsorption of REE onto Fe oxyhydroxide. Journal of Colloid and Interface Science 277, 271-279.

Decarlo, E.H., 1991. Paleoceanographic implications of rare earth element variability within a Fe-Mn crust from the central Pacific Ocean. Marine Geology 98, 449-467.

Dubinin, A.V., Sval'nov, V.N., Berezhnaya, E.D., Rimskaya-Korsakova, M.N., Demidova, T.P., 2013. Geochemistry of trace and minor elements in sediments and manganese micronodules from the Angola Basin. Lithology and Mineral Resources 48, 175-197.

Elderfield, H., Greaves, M.J., 1981. Negative cerium anomalies in the rare earth element patterns of oceanic ferromanganese nodules. Earth and Planetary Science Letters 55, 163-170.

Elderfield, H., Greaves, M.J., 1982. The rare earth elements in seawater. Nature 296, 214-219.

Elderfield, H., Hawkesworth, C.J., Greaves, M.J., Calvert, S.E., 1981. Rare earth element geochemistry of oceanic ferromanganese nodules and associated sediments. Geochimica Et Cosmochimica Acta 45, 513-528.

Elderfield, H., Upstillgoddard, R., Sholkovitz, E.R., 1990. The rare earth elements in rivers, estuaries, and coastal seas and their significance to the composition of ocean waters. Geochimica Et Cosmochimica Acta 54, 971-991.

Elderfield, H., Whitfield, M., Burton, J.D., Bacon, M.P., Liss, P.S., 1988. The Oceanic Chemistry of the Rare-Earth Elements [and Discussion]. Philosophical Transactions of the Royal Society of London. Series A, Mathematical and Physical Sciences 325, 105 126.

Elmore, A.C., Piotrowski, A.M., Wright, J.D., Scrivner, A.E., 2011. Testing the extraction of past seawater $\mathrm{Nd}$ isotopic composition from North Atlantic deep sea sediments and foraminifera. Geochemistry, Geophysics, Geosystems 12, Q09008. 
Felitsyn, S., Morad, S., 2002. REE patterns in latest Neoproterozoic-early Cambrian phosphate concretions and associated organic matter. Chemical Geology 187, 257265.

Filgueiras, A.V., Lavilla, I., Bendicho, C., 2002. Chemical sequential extraction for metal partitioning in environmental solid samples. Journal of Environmental Monitoring 4, 823-857.

Frank, M., 2002. Radiogenic isotopes: Tracers of past ocean circulation and erosional input. Reviews of Geophysics 40, 1-1-1-38.

Freslon, N., Bayon, G., Birot, D., Bollinger, C., Barrat, J.A., 2011. Determination of rare earth elements and other trace elements (Y, Mn, Co, Cr) in seawater using Tm addition and $\mathrm{Mg}(\mathrm{OH})(2)$ co-precipitation. Talanta 85, 582-587.

Froelich, P.N., Klinkhammer, G.P., Bender, M.L., Luedtke, N.A., Heath, G.R., Cullen, D., Dauphin, P., Hammond, D., Hartman, B., Maynard, V., 1979. Early oxidation of organic matter in pelagic sediments of the eastern equatorial Atlantic: suboxic diagenesis. Geochimica et Cosmochimica Acta 43, 1075-1090.

Gaillardet, J., Dupre, B., Allegre, C.J., Négrel, P., 1997. Chemical and physical denudation in the Amazon River Basin. Chemical Geology 142, 141-173.

Goldstein, S.J., Jacobsen, S.B., 1987. THE Nd AND Sr ISOTOPIC SYSTEMATICS OF RIVER-WATER DISSOLVED MATERIAL - IMPLICATIONS FOR THE SOURCES OF Nd AND Sr IN SEAWATER. Chemical Geology 66, 245-272.

Goldstein, S.J., Jacobsen, S.B., 1988a. $\mathrm{Nd}$ and $\mathrm{Sr}$ isotopic systematics of river water suspended material: implications for crustal evolution. Earth and Planetary Science Letters 87, 249-265.

Goldstein, S.J., Jacobsen, S.B., 1988b. Rare earth elements in river waters. Earth and Planetary Science Letters 89, 35-47.

Goldstein, S.J., Jacobsen, S.B., 1988c. REE in the Great Whale River estuary, northwest Quebec. Earth and Planetary Science Letters 88, 241-252.

Goldstein, S.L., Hemming, S.R., 2003. 6.17 - Long-lived Isotopic Tracers in Oceanography, Paleoceanography, and Ice-sheet Dynamics, in: Editors-in-Chief: Heinrich, D.H., Karl, K.T. (Eds.), Treatise on Geochemistry. Pergamon, Oxford, pp. 453-489.

Grousset, F.E., Biscaye, P.E., Zindler, A., Prospero, J., Chester, R., 1988. Neodymium isotopes as tracers in marine sediments and aerosols: North Atlantic. Earth and Planetary Science Letters 87, 367-378.

Gupta, S.K., Chen, K.Y., 1975. PARTITIONING OF TRACE-METALS IN SELECTIVE CHEMICAL FRACTIONS OF NEARSHORE SEDIMENTS. Environmental Letters 10, 129-158.

Gutjahr, M., Frank, M., Stirling, C.H., Klemm, V., van de Flierdt, T., Halliday, A.N., 2007. Reliable extraction of a deepwater trace metal isotope signal from $\mathrm{Fe}-\mathrm{Mn}$ oxyhydroxide coatings of marine sediments. Chemical Geology 242, 351-370. 
Haley, B.A., Klinkhammer, G.P., McManus, J., 2004. Rare earth elements in pore waters of marine sediments. Geochimica Et Cosmochimica Acta 68, 1265-1279.

Hedges, J.I., Keil, R.G., Benner, R., 1997. What happens to terrestrial organic matter in the ocean? Organic Geochemistry 27, 195-212.

Herbert, T.D., 2001. Review of alkenone calibrations (culture, water column, and sediments). Geochemistry, Geophysics, Geosystems 2, 1055.

Himmler, T., Haley, B., Torres, M., Klinkhammer, G., Bohrmann, G., Peckmann, J., 2013. Rare earth element geochemistry in cold-seep pore waters of Hydrate Ridge, northeast Pacific Ocean. Geo-Marine Letters 33, 369-379.

Hopmans, E.C., Weijers, J.W.H., Schefuss, E., Herfort, L., Damste, J.S.S., Schouten, S., 2004. A novel proxy for terrestrial organic matter in sediments based on branched and isoprenoid tetraether lipids. Earth and Planetary Science Letters 224, 107-116.

Hoyle, J., Elderfield, H., Gledhill, A., Greaves, M., 1984. The behaviour of the rare earth elements during mixing of river and sea waters. Geochimica Et Cosmochimica Acta $48,143-149$.

Huon, S., Grousset, F.E., Burdloff, D., Bardoux, G., Mariotti, A., 2002. Sources of fine-sized organic matter in North Atlantic Heinrich layers: delta C-13 and delta N-15 tracers. Geochimica Et Cosmochimica Acta 66, 223-239.

Jacobsen, S.B., Wasserburg, G.J., 1980. Sm-Nd ISOTOPIC EVOLUTION OF CHONDRITES. Earth and Planetary Science Letters 50, 139-155.

Kappler, A., Ji, R., Schink, B., Brune, A., 2001. Dynamics in composition and size-class distribution of humic substances in profundal sediments of Lake Constance. Organic Geochemistry 32, 3-10.

Kasper-Zubillaga, J.J., Rosales-Hoz, L., Bernal, J.P., 2010. Rare earth elements in corals from the Isla de Sacrificios Reef, Veracruz, Mexico. Chemie Der Erde-Geochemistry 70, $55-60$.

Keasler, K.M., Loveland, W.D., 1982. Rare earth elemental concentrations in some Pacific Northwest rivers. Earth and Planetary Science Letters 61, 68-72.

Killops, S., Killops, V., 2004. Production, Preservation and Degradation of Organic Matter, Introduction to Organic Geochemistry. Blackwell Publishing Ltd., pp. 71-116.

Kim, J.-H., Torres, M.E., Haley, B.A., Kastner, M., Pohlman, J.W., Riedel, M., Lee, Y.-J., 2012. The effect of diagenesis and fluid migration on rare earth element distribution in pore fluids of the northern Cascadia accretionary margin. Chemical Geology 291, 152165.

Koeppenkastrop, D., Decarlo, E.H., 1992. Sorption of rare-earth elements from seawater onto synthetic mineral particles: An experimental approach. Chemical Geology 95, 251263. 
Koeppenkastrop, D., Decarlo, E.H., 1993. Uptake of Rare Earth Elements from Solution by Metal Oxides. Environmental Science \& Technology 27, 1796-1802.

Kulaksiz, S., Bau, M., 2013. Anthropogenic dissolved and colloid/nanoparticle-bound samarium, lanthanum and gadolinium in the Rhine River and the impending destruction of the natural rare earth element distribution in rivers. Earth and Planetary Science Letters 362, 43-50.

Lacan, F., Jeandel, C., 2004a. Neodymium isotopic composition and rare earth element concentrations in the deep and intermediate Nordic Seas: Constraints on the Iceland Scotland Overflow Water signature. Geochemistry, Geophysics, Geosystems 5, Q11006.

Lacan, F., Jeandel, C., 2004b. Subpolar Mode Water formation traced by neodymium isotopic composition. Geophysical Research Letters 31, L14306.

Lacan, F., Tachikawa, K., Jeandel, C., 2012. Neodymium isotopic composition of the oceans: A compilation of seawater data. Chemical Geology 300, 177-184.

Lamb, A.L., Wilson, G.P., Leng, M.J., 2006. A review of coastal palaeoclimate and relative sea-level reconstructions using $\delta 13 \mathrm{C}$ and $\mathrm{C} / \mathrm{N}$ ratios in organic material. Earth-Science Reviews 75, 29-57.

Lee, C., Wakeham, S., Arnosti, C., 2004. Particulate Organic Matter in the Sea: The Composition Conundrum. Ambio 33, 565-575.

Lee, J.H., Byrne, R.H., 1992. Examination of comparative rare earth element complexation behavior using linear free-energy relationships. Geochimica Et Cosmochimica Acta $56,1127-1137$.

Lee, J.H., Byrne, R.H., 1993. Complexation of trivalent rare earth elements (Ce, Eu, Gd, Tb, Yb) by carbonate ions. Geochimica Et Cosmochimica Acta 57, 295-302.

Liu, Y., Peng, Z., Wei, G., Chen, T., Sun, W., He, J., Liu, G., Chou, C.-L., Shen, C.-C., 2011. Interannual variation of rare earth element abundances in corals from northern coast of the South China Sea and its relation with sea-level change and human activities. Marine Environmental Research 71, 62-69.

Marsac, R., Davranche, M., Gruau, G., Bouhnik-Le Coz, M., Dia, A., 2011. An improved description of the interactions between rare earth elements and humic acids by modeling: PHREEQC-Model VI coupling. Geochimica Et Cosmochimica Acta 75, 5625-5637.

Meyers, P.A., Ishiwatari, R., 1993. Lacustrine organic geochemistry - an overview of indicators of organic matter sources and diagenesis in lake sediments. Organic Geochemistry 20, 867-900.

Milliman, J.D., Farnsworth, K.L., 2011. River Discharge to the Coastal Ocean, Cambridge.

Moller, P., Bau, M., 1993. Rare-earth patterns with positive cerium anomaly in alkaline waters from Lake Van, Turkey. Earth and Planetary Science Letters 117, 671-676. 
Morgan, B., Rate, A.W., Burton, E.D., Smirk, M.N., 2012. Enrichment and fractionation of rare earth elements in FeS- and organic-rich estuarine sediments receiving acid sulfate soil drainage. Chemical Geology 308-309, 60-73.

Nath, B.N., Balaram, V., Sudhakar, M., Pluger, W.L., 1992. Rare earth element geochemistry of ferromanganese deposits from the Indian Ocean. Marine Chemistry 38, 185-208.

Nothdurft, L.D., Webb, G.E., Kamber, B.S., 2004. Rare earth element geochemistry of Late Devonian reefal carbonates, canning basin, Western Australia: Confirmation of a seawater REE proxy in ancient limestones. Geochimica Et Cosmochimica Acta 68, 263-283.

Nozaki, Y., 2001. Rare Earth Elements and their Isotopes in the Ocean, in: Editor-inChief: John, H.S. (Ed.), Encyclopedia of Ocean Sciences. Academic Press, Oxford, pp. 2354-2366.

Nozaki, Y., Lerche, D., Alibo, D.S., Snidvongs, A., 2000. The estuarine geochemistry of rare earth elements and indium in the Chao Phraya River, Thailand. Geochimica Et Cosmochimica Acta 64, 3983-3994.

Ohlander, B., Ingri, J., Land, M., Schoberg, H., 2000. Change of Sm-Nd isotope composition during weathering of till. Geochimica Et Cosmochimica Acta 64, 813-820.

Ohta, A., Kawabe, I., 2001. REE(III) adsorption onto Mn dioxide (delta-MnO2) and Fe oxyhydroxide: $\mathrm{Ce}$ (III) oxidation by delta-MnO2. Geochimica Et Cosmochimica Acta 65, 695-703.

Omoregie, E.O., Mastalerz, V., de lange, G., Straub, K.L., Kappler, A., Roy, H., Stadnitskaia, A., Foucher, J.-P., Boetius, A., 2008. Biogeochemistry and community composition of iron- and sulfur-precipitating microbial mats at the Chefren mud volcano (Nile Deep Sea fan, Eastern Mediterranean). Applied and Environmental Microbiology 74, 31983215 .

Palmer, M.R., Elderfield, H., 1986. Rare earth elements and neodymium isotopes in ferromanganese oxide coatings of Cenozoic foraminifera from the Atlantic Ocean. Geochimica Et Cosmochimica Acta 50, 409-417.

Piepgras, D.J., Wasserburg, G.J., 1980. NEODYMIUM ISOTOPIC VARIATIONS IN SEAWATER. Earth and Planetary Science Letters 50, 128-138.

Piepgras, D.J., Wasserburg, G.J., 1987. Rare earth element transport in the western North Atlantic inferred from $\mathrm{Nd}$ isotopic observations. Geochimica Et Cosmochimica Acta $51,1257-1271$.

Pokrovsky, O.S., Schott, J., Dupre, B., 2006. Trace element fractionation and transport in boreal rivers and soil porewaters of permafrost-dominated basaltic terrain in Central Siberia. Geochimica Et Cosmochimica Acta 70, 3239-3260.

Pourret, O., Davranche, M., Gruau, G., Dia, A., 2007a. Competition between humic acid and carbonates for rare earth elements complexation. Journal of Colloid and Interface Science 305, 25-31. 
Pourret, O., Davranche, M., Gruau, G., Dia, A., 2007b. Organic complexation of rare earth elements in natural waters: Evaluating model calculations from ultrafiltration data. Geochimica Et Cosmochimica Acta 71, 2718-2735.

Pourret, O., Davranche, M., Gruau, G., Dia, A., 2007c. Rare earth elements complexation with humic acid. Chemical Geology 243, 128-141.

Pourret, O., Davranche, M., Gruau, G., Dia, A., 2008. New insights into cerium anomalies in organic-rich alkaline waters. Chemical Geology 251, 120-127.

Rickli, J., Frank, M., Baker, A.R., Aciego, S., de Souza, G., Georg, R.B., Halliday, A.N., 2010. Hafnium and neodymium isotopes in surface waters of the eastern Atlantic Ocean: Implications for sources and inputs of trace metals to the ocean. Geochimica Et Cosmochimica Acta 74, 540-557.

Schouten, S., Hopmans, E.C., Schefuss, E., Damste, J.S.S., 2002. Distributional variations in marine crenarchaeotal membrane lipids: a new tool for reconstructing ancient sea water temperatures? Earth and Planetary Science Letters 204, 265-274.

Shiller, A.M., 2010. Dissolved rare earth elements in a seasonally snow-covered, alpine/subalpine watershed, Loch Vale, Colorado. Geochimica Et Cosmochimica Acta $74,2040-2052$.

Sholkovitz, E., Shen, G.T., 1995. The incorporation of rare earth elements in modern coral. Geochimica Et Cosmochimica Acta 59, 2749-2756.

Sholkovitz, E., Szymczak, R., 2000. The estuarine chemistry of rare earth elements: comparison of the Amazon, Fly, Sepik and the Gulf of Papua systems. Earth and Planetary Science Letters 179, 299-309.

Sholkovitz, E.R., 1992. Chemical evolution of rare earth elements: fractionation between colloidal and solution phases of filtered river water. Earth and Planetary Science Letters 114, 77-84.

Sholkovitz, E.R., Landing, W.M., Lewis, B.L., 1994. Ocean particle chemistry: The fractionation of rare earth elements between suspended particles and seawater. Geochimica Et Cosmochimica Acta 58, 1567-1579.

Sibuet, M., Olu, K., 1998. Biogeography, biodiversity and fluid dependence of deep-sea coldseep communities at active and passive margins. Deep Sea Research Part II: Topical Studies in Oceanography 45, 517-567.

Soulet, G., Menot, G., Bayon, G., Rostek, F., Ponzevera, E., Toucanne, S., Lericolais, G., Bard, E., 2013. Abrupt drainage cycles of the Fennoscandian Ice Sheet. Proceedings of the National Academy of Sciences of the United States of America 110, 6682-6687.

Soyol-Erdene, T.-O., Huh, Y., 2013. Rare earth element cycling in the pore waters of the Bering Sea Slope (IODP Exp. 323). Chemical Geology 358, 75-89.

Stolpe, B., Guo, L., Shiller, A.M., 2013. Binding and transport of rare earth elements by organic and iron-rich nanocolloids in Alaskan rivers, as revealed by field-flow fractionation and ICP-MS. Geochimica Et Cosmochimica Acta 106, 446-462. 
Tachikawa, K., Jeandel, C., Vangriesheim, A., Dupre, B., 1999. Distribution of rare earth elements and neodymium isotopes in suspended particles of the tropical Atlantic Ocean (EUMELI site). Deep-Sea Research I 46, 733-755.

Tachikawa, K., Athias, V., Jeandel, C., 2003. Neodymium budget in the modern ocean and paleo-oceanographic implications. Journal of Geophysical Research: Oceans 108, 3254.

Tachikawa, K., Roy-Barman, M., Michard, A., Thouron, D., Yeghicheyan, D., Jeandel, C., 2004. Neodymium isotopes in the Mediterranean Sea: Comparison between seawater and sediment signals. Geochimica Et Cosmochimica Acta 68, 3095-3106.

Tachikawa, K., Toyofuku, T., Basile-Doelsch, I., Delhaye, T., 2013. Microscale neodymium distribution in sedimentary planktonic foraminiferal tests and associated mineral phases. Geochimica et Cosmochimica Acta 100, 11-23.

Tachikawa, K., Piotrowski, A.M., Bayon, G., 2014. Neodymium associated with foraminiferal carbonate as a recorder of seawater isotopic signatures. Quaternary Science Reviews 88, 1-13.

Tanaka, T., Togashi, S., Kamioka, H., Amakawa, H., Kagami, H., Hamamoto, T., Yuhara, M., Orihashi, Y., Yoneda, S., Shimizu, H., Kunimaru, T., Takahashi, K., Yanagi, T., Nakano, T., Fujimaki, H., Shinjo, R., Asahara, Y., Tanimizu, M., Dragusanu, C., 2000. JNdi-1: a neodymium isotopic reference in consistency with LaJolla neodymium. Chemical Geology 168, 279-281.

Taylor, S.R., McLennan, S.M., 1985. The Continental Crust: Its composition and Evolution. An Examination of the Geochemical Record Preserved in Sedimentary Rocks. Blackwell Scientific Publications, Oxford.

Tazoe, H., Obata, H., Gamo, T., 2011. Coupled isotopic systematics of surface cerium and neodymium in the Pacific Ocean. Geochemistry, Geophysics, Geosystems 12, Q04004.

Tessier, A., Campbell, P.G.C., Bisson, M., 1979. Sequential Extraction Procedure for the Speciation of Particulate Trace Metals. Analytical Chemistry 51, 844-851.

Toucanne, S., Bayon, G., Soulet, G., Freslon, N., Silva Jacinto, R., Barker, S., Dennielou, B., Zaragosi, S., Eynaud, F., Bourillet, J.-F., 2013. Role of the European ice sheet complex during Early Deglaciation. Science, submission pending.

Treignier, C., Derenne, S., Saliot, A., 2006. Terrestrial and marine n-alcohol inputs and degradation processes relating to a sudden turbidity current in the Zaire canyon. Organic Geochemistry 37, 1170-1184.

Tribovillard, N., Algeo, T.J., Lyons, T., Riboulleau, A., 2006. Trace metals as paleoredox and paleoproductivity proxies: An update. Chemical Geology 232, 12-32.

Vance, D., Burton, K., 1999. Neodymium isotopes in planktonic foraminifera: a record of the response of continental weathering and ocean circulation rates to climate change. Earth and Planetary Science Letters 173, 365-379. 
Vance, D., Scrivner, A.E., Beney, P., Staubwasser, M., Henderson, G.M., Slowey, N.C., 2004. The use of foraminifera as a record of the past neodymium isotope composition of seawater. Paleoceanography 19, PA2009.

Wakeham, S.G., Lee, C., 1989. Organic geochemistry of particulate matter in the ocean: The role of particles in oceanic sedimentary cycles. Organic Geochemistry 14, 83-96.

Webb, G.E., Kamber, B.S., 2000. Rare earth elements in Holocene reefal microbialites: A new shallow seawater proxy. Geochimica Et Cosmochimica Acta 64, 1557-1565.

Weijers, J.W.H., Schouten, S., van den Donker, J.C., Hopmans, E.C., Damste, J.S.S., 2007. Environmental controls on bacterial tetraether membrane lipid distribution in soils. Geochimica Et Cosmochimica Acta 71, 703-713.

Wyndham, T., McCulloch, M., Fallon, S., Alibert, C., 2004. High-resolution coral records of rare earth elements in coastal seawater: Biogeochemical cycling and a new environmental proxy. Geochimica Et Cosmochimica Acta 68, 2067-2080.

Xu, Z., Han, G., 2009. Rare earth elements (REE) of dissolved and suspended loads in the Xijiang River, South China. Applied Geochemistry 24, 1803-1816.

Zhang, Z., Du, Y., Gao, L., Zhang, Y., Shi, G., Liu, C., Zhang, P., Duan, X., 2012. Enrichment of REEs in polymetallic nodules and crusts and its potential for exploitation. Journal of Rare Earths 30, 621-626.

Zhou, J., Huang, Z., Zhou, G., Li, X., Ding, W., Bao, G., 2011. Trace Elements and Rare Earth Elements of Sulfide Minerals in the Tianqiao Pb-Zn Ore Deposit, Guizhou Province, China. Acta Geologica Sinica-English Edition 85, 189-199.

\section{TABLE CAPTIONS}

\section{Table 1: Location of the studied sediment $(n=70)$ and surface seawater $(n=3)$ samples}

Sediment samples are divided in four groups depending on their depositional environment: 'Rivers' ( $\mathrm{n}=25)$, 'Estuaries' $(\mathrm{n}=18)$, 'Ocean' $(\mathrm{n}=15)$, and 'Cold seeps' $(\mathrm{n}=12)$. The number ID is the same for all tables on this paper.

\section{Table 2: Total mass of sediment (mg), Ca, Fe (mg) and REE ( $\mu$ g) leached during experimental tests}

Different sequential leaching procedures were evaluated prior to the extraction of sedimentary organic matter using mixed $\mathrm{H}_{2} \mathrm{O}_{2}-\mathrm{HNO}_{3}$ solution. A series of experiments were conducted to assess the impact of various carbonate/oxy-hydroxide leaching steps on the extraction of 
organic matter by mixed $\mathrm{H}_{2} \mathrm{O}_{2}$ - dilute nitric solution (see text for details). These experiments were performed on two sediment samples: one sediment from the Murray River (Australia; \#7), and one carbonate-rich marine sediment from the North Atlantic (\#56). Values between brackets correspond to those obtained on the following $\mathrm{H}_{2} \mathrm{O}_{2}$ leachates. Standard errors are not presented but were always fewer than $10 \%$.

Table 3: Rare earth element and Nd isotopic data for sedimentary organic matter, terrigenous fractions and nearest surface seawater

The mass fraction of total sediment extracted by $\mathrm{H}_{2} \mathrm{O}_{2}$ is noted $\mathrm{OM}$ (\%wt/wt) and Total Organic Carbon is noted TOC (\%wt/wt). Standard errors for REE abundances are below 5\%. Ce anomalies $\left(\mathrm{Ce} / \mathrm{Ce}^{*}\right)$ were determined using the equation $2 * \mathrm{Ce}_{\mathrm{N}} /\left[\mathrm{La}_{\mathrm{N}}+\mathrm{Pr}_{\mathrm{N}}\right]$, with $\mathrm{N}$ corresponding to REE concentration normalized to PAAS. The external reproducibility for Neodymium isotopic measurements is below 0.3 (noted as $\varepsilon N d$ ). Detrital $\varepsilon N d$ values with * are from Toucanne et al., submitted and ** are from Soulet et al., 2013. The data for $\mathrm{Nd}$ isotopes in surface waters are from: A: Tazoe et al., 2011. B: Piepgras and Wasserburg, 1987. C: Rickli et al., 2010. D: Piepgras and Wasserburg, 1980. E: Amakawa et al., 2000. F: Vance et al., 2004. G: Lacan and Jeandel, 2004b. H: Lacan and Jeandel, 2004a. I: Bertram and Elderfield, 1993. J: Bayon et al., 2011b. K: Tachikawa et al., 2004. The corresponding analytical errors are usually below 0.5 \&-units.

Table 4: Total mass leached by $\mathrm{H}_{2} \mathrm{O}_{2}$, REE and Nd isotopic compositions for MAG-1 and SGR-1

The mass fraction of total sediment extracted by $\mathrm{H}_{2} \mathrm{O}_{2}$ is noted $\mathrm{OM}(\% \mathrm{wt} / \mathrm{wt})$.

\section{Table 5: Typical REE concentrations in natural waters and marine precipitates}

The average REE concentrations for sedimentary organic matter (This study) are compared with non-exhaustive synthetical data from the literature for: Fe-Mn nodules/crusts (Decarlo, 1991; Dubinin et al., 2013; Elderfield et al., 1981; Nath et al., 1992; Zhang et al., 2012), FeMn oxyhydroxide coatings from marine sediments or foraminifera (Bayon et al., 2004; Charbonnier et al., 2012; Palmer and Elderfield, 1986), Biogenic carbonates: (Akagi et al., 2004; Charbonnier et al., 2012; Kasper-Zubillaga et al., 2010; Liu et al., 2011; Nothdurft et al., 2004; Sholkovitz and Shen, 1995; Webb and Kamber, 2000; Wyndham et al., 2004), Anoxic pore water: (Bayon et al., 2011b), River water: (Elderfield et al., 1990; Goldstein and 
Jacobsen, 1988b, c; Hoyle et al., 1984; Keasler and Loveland, 1982; Kulaksiz and Bau, 2013; Nozaki et al., 2000; Pokrovsky et al., 2006; Shiller, 2010; Stolpe et al., 2013; Xu and Han, 2009). Average REE data for seawater are from Nozaki, 2001. The REE concentrations for PAAS used for normalization on Figure 3 and Figure 6 are given by Taylor and McLennan, 1985.

\section{FIGURE CAPTIONS}

Figure 1: Location of the studied sediment $(n=70)$ and seawater $(n=3)$ samples

Figure 2: Results from experimental investigations (total mass of leached sediment, Ca, Fe, REE)

See text for details. Different leaching procedures for carbonate and Fe-Mn oxide removal prior to extraction of organic compounds using $\mathrm{H}_{2} \mathrm{O}_{2}$ were performed on (a) a marine sediment sample (North Atlantic Ocean; \#56), and (b) a river sediment (Murray River; \#7). Their impact on the subsequent $\mathrm{H}_{2} \mathrm{O}_{2}$ leach is shown respectively in (c) and (d). Error bars correspond to $2 \mathrm{~s}$. Note that each of these experiments was conducted on separate bulk sediment samples.

\section{Figure 3: Shale-normalized (PAAS) REE patterns}

PAAS-normalized REE abundances for organic fractions extracted from sediments according to their depositional environment: (a) Rivers, (b) Estuaries, (c) Ocean, (d) Cold seeps. Average values for each group are presented in (e).

Figure 4: Neodymium isotopic composition of sedimentary organic matter versus terrigenous fraction

River sediments generally exhibit a similar $\varepsilon N d$ signature for both organic matter and terrigenous fraction, while larger differences between those two fractions are more frequent in marine samples $(\Delta \varepsilon \mathrm{Nd}>1)$. Analytical errors $(2 \mathrm{~s})$ are comprised in the symbol size. The grey line corresponds to the slope $1: 1$. 
Figure 5: Comparison of Nd isotopic compositions for sedimentary organic matter with corresponding surface seawater and detrital \&Nd values for (a) oceanic and (b) cold seep samples

The Nd isotopic composition of the terrigenous fraction of the sediment (also called detrital material) is taken as representative of the signature of associated terrestrial organic matter. Local surface seawater $\varepsilon \mathrm{Nd}$ values represent the end-member for the Nd isotopic signature of marine organic compounds. Sample ID corresponds to the number of the sample (Table 1).

Figure 6: Average shale-normalized (PAAS) REE patterns for natural waters (seawater, river water, anoxic pore water), sedimentary organic matter and marine precipitates (deep-ocean Fe-Mn crusts/nodules, marine Fe-Mn oxy-hydroxide, biogenic carbonates) See corresponding data in Table 5. 


\begin{tabular}{|c|c|c|c|}
\hline ID & Localisation & Lat & Long \\
\hline \multicolumn{4}{|c|}{ Rivers $(n=25)$} \\
\hline 1 & Amu-Daria (Kipchaq, Uzbekistan) & N 42¹3'20" & E $060^{\circ} 06^{\prime} 55^{\prime \prime}$ \\
\hline 2 & Avière (Uxegney, France) & N 48 $10^{\prime} 55^{\prime \prime}$ & E $006^{\circ} 23^{\prime} 26^{\prime \prime}$ \\
\hline 3 & Benue (Dangerri, Nigeria) & N 0751'44" & E $006^{\circ} 53^{\prime} 21^{\prime \prime}$ \\
\hline 4 & Daugauva, Dvina Occ. (Latvia) & N 57 $36^{\prime} 00^{\prime \prime}$ & E $024^{\circ} 23^{\prime} 24^{\prime \prime}$ \\
\hline 5 & Desna (Maxim, Ukraine) & N 511'ㅇ' & E $030^{\circ} 56^{\prime} 40^{\prime \prime}$ \\
\hline 6 & Elbe (Hambourg, Germany) & N $53^{\circ} 32^{\prime} 54^{\prime \prime}$ & E $009^{\circ} 48^{\prime} 36^{\prime \prime}$ \\
\hline 7 & Murray River (Lake Alexandrina; Australia) & S $35^{\circ} 24^{\prime} 37^{\prime \prime}$ & E $139^{\circ} 13^{\prime} 47^{\prime \prime}$ \\
\hline 8 & Orne (Etaveau, France) & N 4907'59" & W $000^{\circ} 24^{\prime} 04^{\prime \prime}$ \\
\hline 9 & Red river, Song Hong (Thai Binh, Vietnam) & N 20¹5'26" & E $106^{\circ} 30^{\prime} 57^{\prime \prime}$ \\
\hline 10 & Rio Orinoco (Caicara del Orinoco, Venezuela) & N $07^{\circ} 38^{\prime} 52^{\prime \prime}$ & W $066^{\circ} 10^{\prime} 53^{\prime \prime}$ \\
\hline 11 & Upper Dniepr (Liubeck, Ukraine) & N $51^{\circ} 42^{\prime} 47^{\prime \prime}$ & E $030^{\circ} 37^{\prime} 37^{\prime \prime}$ \\
\hline 12 & Volga delta (Astrakhan', Russia) & $\mathrm{N} 45^{\circ} 42^{\prime} 47^{\prime \prime}$ & E $047^{\circ} 55^{\prime} 12^{\prime \prime}$ \\
\hline 13 & Ellez (Botmeur, France) & N 4821'40" & W $003^{\circ} 55^{\prime} 25^{\prime \prime}$ \\
\hline 14 & Fao (Huelgoat, France) & $\mathrm{N} 48^{\circ} 21^{\prime} 40^{\prime \prime}$ & W $003^{\circ} 46^{\prime} 03^{\prime \prime}$ \\
\hline 15 & Glomma (Fetsund, Norway) & N 59॰55'44" & E $011^{\circ} 09^{\prime} 44^{\prime \prime}$ \\
\hline 16 & Kiiminkijoki (Kiiminki ,Finland) & N 65ㅇำ $60^{\prime \prime}$ & E $025^{\circ} 43^{\prime} 52^{\prime \prime}$ \\
\hline 17 & Kymijoki (Kotka, Finland) & N 60²7'36" & E $026^{\circ} 54^{\prime} 36^{\prime \prime}$ \\
\hline 18 & Mare aux sangliers (Huelgoat, France) & N 4822'14" & W $003^{\circ} 44^{\prime} 12^{\prime \prime}$ \\
\hline 19 & Rio Aro (Rio Aro, Venezuela) & N 07²3'36" & W $064^{\circ} 00^{\prime} 49^{\prime \prime}$ \\
\hline 20 & Rio Caura (Aurora, Venezuela) & N 07³4'59" & 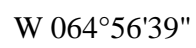 \\
\hline 21 & Rio Cuchivero (Cuchivero, Venezuela) & N 07³9'29" & W $065^{\circ} 57^{\prime} 24^{\prime \prime}$ \\
\hline 22 & Rivière des Galets (Le Port, Reunion island) & S $20^{\circ} 57^{\prime} 04^{\prime \prime}$ & E $055^{\circ} 18^{\prime} 03^{\prime \prime}$ \\
\hline 23 & Rivière des Galets (Le Port, Reunion island) & S $20^{\circ} 57^{\prime} 41^{\prime \prime}$ & E $055^{\circ} 18^{\prime} 26^{\prime \prime}$ \\
\hline 24 & Tagus (Alochete, Portugal) & N 3846'15" & W $008^{\circ} 56^{\prime} 46^{\prime \prime}$ \\
\hline 25 & Ume (Umea, Sweden) & N 634ㄱ'07" & E $020^{\circ} 16^{\prime} 19^{\prime \prime}$ \\
\hline \multicolumn{4}{|c|}{ Estuaries $(n=18)$} \\
\hline 26 & Adour (Bayonne, France) & N 43⒉'20" & W 001 $27^{\circ} 56^{\prime \prime}$ \\
\hline 27 & Douro (Avintes, Portugal) & $\mathrm{N} 41^{\circ} 07^{\prime} 06^{\prime \prime}$ & W $008^{\circ} 32^{\prime} 56^{\prime \prime}$ \\
\hline 28 & Dvina (Severodvinsk, Russia) & 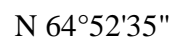 & E $039^{\circ} 57^{\prime} 52^{\prime \prime}$ \\
\hline 29 & Elorn (Le Relecq-Kerhuon, France) & N 4823'48" & W $004^{\circ} 22^{\prime} 48^{\prime \prime}$ \\
\hline 30 & Gauja (Sigulda, Latvia) & N $57^{\circ} 07^{\prime} 60^{\prime \prime}$ & E $024^{\circ} 41^{\prime} 04^{\prime \prime}$ \\
\hline 31 & Loire (Frossay, France) & N 47016'31" & W 00153'59" \\
\hline 32 & Nalon (San Piedro, Spain) & N 433'이" & W $006^{\circ} 04^{\prime} 46^{\prime \prime}$ \\
\hline 33 & Neman (Silute, Lithuania) & N 552'ㄴ' & E $021^{\circ} 15^{\prime} 25^{\prime \prime}$ \\
\hline 34 & Rhine (Rotterdam, Netherlands) & N 51ํ54'34" & E $004^{\circ} 29^{\prime} 03^{\prime \prime}$ \\
\hline 35 & Rio Landro (Viveiro, Spain) & N 433'ㄷㄴ" & W 007³5'56" \\
\hline 36 & Rio Marabal (Marabal, Venezuela) & N 10³5'38" & W $062^{\circ} 42^{\prime} 07^{\prime \prime}$ \\
\hline 37 & Sefid-Rud (Rasht, Iran) & N 37은' $55^{\prime \prime}$ & E $049^{\circ} 56^{\prime} 15^{\prime \prime}$ \\
\hline 38 & Seine (Tancarville, France) & N 49²7'17" & E $000^{\circ} 25^{\prime} 08^{\prime \prime}$ \\
\hline 39 & Shannon (Shannon, Eire) & N $52^{\circ} 41^{\prime} 22^{\prime \prime}$ & W $008^{\circ} 54^{\prime} 36^{\prime \prime}$ \\
\hline 40 & Tay river (Perth, Scotland) & N 56º $31^{\prime} 10^{\prime \prime}$ & W $003^{\circ} 14^{\prime} 03^{\prime \prime}$ \\
\hline 41 & Vistula (Gdansk, Poland) & N 54 $39^{\prime} 03^{\prime \prime}$ & E $019^{\circ} 16^{\prime} 58^{\prime \prime}$ \\
\hline 42 & Weser (Bremerhaven, Germany) & N 533' $19 "$ & E $008^{\circ} 34^{\prime} 19^{\prime \prime}$ \\
\hline 43 & Yangtze (Shanghai, China) & N 313'ㄹ" & E $121^{\circ} 23 ' 38^{\prime \prime}$ \\
\hline \multicolumn{4}{|c|}{ Ocean $(n=15)$} \\
\hline 44 & Baffin bay (NW Atlantic) - MD99-2232 (0-1cm) & N 62³8'59" & W 0535'ㅇ" \\
\hline 45 & Bermuda Rise (tropical NW Atlantic) - IODP-172-1063C $(0-5 \mathrm{~cm})$ & N 334'1'" & W 057036'54" \\
\hline 46 & Biscay bay (NE Atlantic) - KECP-11 (0-1cm) & $\mathrm{N} 47^{\circ} 27^{\prime} 07^{\prime \prime}$ & W $008^{\circ} 32^{\prime} 02^{\prime \prime}$ \\
\hline 47 & Blake Ridge (NW Atlantic) - IODP-172-1061-A (0-5cm) & N 2958'30" & W $073^{\circ} 35^{\prime} 60^{\prime \prime}$ \\
\hline 48 & China sea (NW Pacific) - MD97-2145 (0-1cm) & N 21 $1^{\circ} 15^{\prime} 56^{\prime \prime}$ & E $120^{\circ} 25^{\prime} 16^{\prime \prime}$ \\
\hline 49 & China sea (NW Pacific) - MD97-2149 (12-13cm) & N 11 $54^{\circ} 00^{\prime \prime}$ & E $110^{\circ} 00^{\prime} 32^{\prime \prime}$ \\
\hline 50 & Congo basin (SE Atlantic) - KZAI-01 (2-3cm) & S $05^{\circ} 42^{\prime} 11^{\prime \prime}$ & E $011^{\circ} 14^{\prime} 01^{\prime \prime}$ \\
\hline 51 & Gulf of Guinea (SE Atlantic) - WACS Push-Core \#1 (0-2cm) & & \\
\hline 52 & Hawaiian Arch (N Pacific) - IODP-136-843-C (0-5cm) & N 19²0'42" & W $159^{\circ} 05^{\prime} 43^{\prime \prime}$ \\
\hline 53 & Japan sea (NW Pacific) - MD01-2410 (0-1cm) & $\mathrm{N} 41^{\circ} 08^{\prime} 37^{\prime \prime}$ & E $143^{\circ} 23^{\prime} 20^{\prime \prime}$ \\
\hline 54 & Japan sea (NW Pacific) - MD01-2419 (0-1cm) & N 3853'01" & E $143^{\circ} 19^{\prime} 26^{\prime \prime}$ \\
\hline 55 & Mediterranean sea - NL5-BC1 $(0-5 \mathrm{~cm})$ & N $32^{\circ} 13^{\prime} 15^{\prime \prime}$ & E $028^{\circ} 13^{\prime} 06^{\prime \prime}$ \\
\hline
\end{tabular}




\begin{tabular}{|c|c|c|c|}
\hline & Gulf of Guinea & & \\
\hline 59 & ERCS-01 ext. & N 0315'05" & E $006^{\circ} 41^{\prime} 50^{\prime \prime}$ \\
\hline 60 & ERCS-02 B2 (50-52) 151 & N 031' $55^{\prime \prime}$ & E $006^{\circ} 41^{\prime} 45^{\prime \prime}$ \\
\hline 61 & ERCS-02 B5 (80-85) 481 & N 031' $55^{\prime \prime}$ & E $006^{\circ} 41^{\prime} 45^{\prime \prime}$ \\
\hline 62 & PL05-CT1 GB (0-5cm) & S $05^{\circ} 47^{\prime} 55^{\prime \prime}$ & E $009^{\circ} 42^{\prime} 33^{\prime \prime}$ \\
\hline \multirow[t]{2}{*}{63} & PL431-CT Kouilou (0-5) & S $04^{\circ} 45^{\prime} 36^{\prime \prime}$ & E $009^{\circ} 56^{\prime} 30^{\prime \prime}$ \\
\hline & Mediterranean sea, Nile margins & & \\
\hline 64 & NL11-BC1 $(0-1 \mathrm{~cm})$ & N 32²2'09" & E $031^{\circ} 42^{\prime} 38^{\prime \prime}$ \\
\hline 65 & NL12-PC4 (1-2cm) & N 32²2'09" & E $031^{\circ} 42^{\prime} 36^{\prime \prime}$ \\
\hline 66 & NL14-PC1 (0.5-1cm) & N 32³8'20" & E $029^{\circ} 55^{\prime} 48^{\prime \prime}$ \\
\hline 67 & NL14-PC1 (17-19cm) & N 32³8'20" & E $029^{\circ} 55^{\prime} 48^{\prime \prime}$ \\
\hline 68 & NL18-BC1 (2-3cm) & N 3206'44" & E $028^{\circ} 10^{\prime} 21^{\prime \prime}$ \\
\hline 69 & NL18-BC1 (5-10cm) & N 3206'44" & E $028^{\circ} 10^{\prime} 21^{\prime \prime}$ \\
\hline 70 & NL21-PC7 (14-16cm) & N 334' $42^{\prime \prime}$ & E $024^{\circ} 40^{\prime} 51^{\prime \prime}$ \\
\hline \multicolumn{4}{|c|}{ Surface Seawater $(n=3)$} \\
\hline 71 & Dellec (1m depth, Jan. 2010, Bay of Brest, NW France) & N 4821'15" & W 0043' $46^{\prime \prime}$ \\
\hline 72 & Gabon margin (5m depth, Feb. 2011, Gulf of Guinea, W Africa) & S $01^{\circ} 37^{\prime} 43^{\prime \prime}$ & E $008^{\circ} 33^{\prime} 02^{\prime \prime}$ \\
\hline 73 & Congo margin (5m depth, Feb. 2011, Gulf of Guinea,W Africa) & S $04^{\circ} 45^{\prime} 36^{\prime \prime}$ & E $009^{\circ} 56^{\prime} 35^{\prime \prime}$ \\
\hline
\end{tabular}


Table 2

\section{North Atlantic Ocean: KN166-14 8 GGC (0-2cm)}

$10 \%$ AA (10ml; $\left.15 \mathrm{~h} ; 20^{\circ} \mathrm{C}\right)$, then $25 \%$ AA + $\mathrm{HH} 1 \mathrm{M}\left(10 \mathrm{ml} ; 4 \mathrm{~h} ; 20^{\circ} \mathrm{C}\right)$

$\mathrm{HCl} 0.25 \mathrm{M}\left(15 \mathrm{ml} ; 1 \mathrm{~h} ; 8^{\circ} \mathrm{C}\right) \mathrm{x} 1$ HCl $0.25 \mathrm{M}\left(15 \mathrm{ml} ; 1 \mathrm{~h} ; 85^{\circ} \mathrm{C}\right) \mathrm{x} 2$ $\mathrm{HCl} 0.25 \mathrm{M}\left(15 \mathrm{ml} ; 1 \mathrm{~h} ; 85^{\circ} \mathrm{C}\right) \mathrm{x} 3$ $\mathrm{HCl} 0.25 \mathrm{M}\left(15 \mathrm{ml} ; 1 \mathrm{~h} ; 85^{\circ} \mathrm{C}\right) \mathrm{x} 4$

$\mathrm{HCl} 1 \mathrm{M}\left(15 \mathrm{ml} ; 3 \mathrm{~h} ; 85^{\circ} \mathrm{C}\right)$ $\mathrm{HCl}$ 6M (15ml; 3h; $\left.85^{\circ} \mathrm{C}\right)$ mass leached (mg)

333.1

208.2

319.3

346,0

354.6

357.8

366,0
(21.6)

(126.3)

(42.2)

(21.2)

(20.3)

(19.6)

(18.3)
Ca $(\mu g)$

$\mathrm{Fe}(\mu \mathrm{g})$

EREE ( $\mu g)$

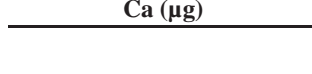

108095

(43)

1554

(787)

26.3

$(0.5)$

\section{5}

(32 433)

(1 140)

(184)

(140)

113962

(1 126)

107687

102850

(1 333)

$\begin{array}{llll}47 & \text { (79) } & 7.1 & \text { (2.2) }\end{array}$

1395

(1 372)

(1 584)

(2 023)

4995

(516)

(254)

7657

37.2

Total sediment

125393

12985

\section{Murray river (Lake Alexandrina, Australia)}

$10 \% \mathrm{AA}\left(10 \mathrm{ml} ; 15 \mathrm{~h} ; 20^{\circ} \mathrm{C}\right)$, then $25 \% \mathrm{AA}+$ $\mathrm{HH} 1 \mathrm{M}\left(10 \mathrm{ml} ; 4 \mathrm{~h} ; 20^{\circ} \mathrm{C}\right)$

22.2

(50.0)

894

(3)

$2418 \quad(1070)$

54.5

(0.7)

HCl 0.25M (15ml; $\left.1 \mathrm{~h} ; 85^{\circ} \mathrm{C}\right) \mathrm{x} 1$

37.0

(45.5)

$\mathrm{HCl} 0.25 \mathrm{M}\left(15 \mathrm{ml} ; 1 \mathrm{~h} ; 8^{\circ} \mathrm{C}\right) \mathrm{x} 2$

48.2

(44.4)

$\mathrm{HCl} 0.25 \mathrm{M}\left(15 \mathrm{ml} ; 1 \mathrm{~h} ; 8^{\circ} \mathrm{C}\right) \mathrm{x} 3$

53.0

(48.1)

$\mathrm{HCl} 0.25 \mathrm{M}\left(15 \mathrm{ml} ; 1 \mathrm{~h} ; 85^{\circ} \mathrm{C}\right) \mathrm{x} 4$

49.2

(49.1)

686

(43)

2017

(1 260)

(20)

3394

(1542)

4498

(1 245)

(40)

5611

(1 083)

45.3

(6.7)

881

(40)

6487

(1 066)

(25)

10268

(209)

31579 
ORGANIC

DETRITIC SURFACE SEAWATER

\begin{tabular}{|c|c|c|c|c|c|c|c|c|c|c|c|c|c|c|c|c|c|c|c|c|}
\hline & (\%wt $/ v$ & & $(\overline{p p m})$ & & & & & & & & & & & & & & & & & \\
\hline ID & $\mathrm{OM}$ & TOC & $\mathrm{La}$ & $\mathrm{Ce}$ & $\mathrm{Pr}$ & Nd & Sm & Eu & Gd & $\mathrm{Tb}$ & Dy & Ho & Er & $\mathrm{Yb}$ & Lu & EREE & $\overline{\mathrm{Ce} / \mathrm{Ce}{ }^{*}}$ & $\varepsilon N d \pm 0.3$ & $\varepsilon \mathrm{Nd} \pm 0.3$ & $\varepsilon \mathrm{Nd} \pm 0.5$ \\
\hline River & $s(n=25)$ & & & & & & & & & & & & & & & & & & & \\
\hline 1 & 5.2 & & 8.5 & 18.9 & 2.4 & 9.7 & 2.2 & 0.5 & 2.3 & 0.4 & 2.6 & 0.49 & 1.3 & 1.07 & 0.13 & 51 & 0.96 & -6.4 & -9.5 & \\
\hline 2 & 5.9 & & 7.5 & 20.0 & 2.6 & 10.8 & 2.4 & 0.5 & 2.0 & 0.3 & 1.4 & 0.25 & 0.6 & 0.51 & 0.07 & 49 & 1.02 & -9.0 & -10.7 & \\
\hline 3 & 11.7 & 3.2 & 44.4 & 125 & 12.2 & 45.9 & 8.2 & 1.6 & 5.9 & 0.8 & 4.0 & 0.71 & 1.9 & 1.61 & 0.24 & 253 & 1.23 & -11.3 & -11.9 & \\
\hline 4 & 11.3 & & 11.4 & 28.7 & 3.5 & 13.1 & 2.2 & 0.4 & 1.8 & 0.2 & 1.0 & 0.18 & 0.5 & 0.41 & 0.06 & 64 & 1.04 & -15.8 & $-15.5 * *$ & \\
\hline 5 & 9.6 & & 24.4 & 58.0 & 7.5 & 30.5 & 5.8 & 1.2 & 5.4 & 0.7 & 3.7 & 0.72 & 2.1 & 1.96 & 0.29 & 143 & 0.98 & -12.3 & -12.6 & \\
\hline 6 & 8.8 & 3.6 & 20.3 & 48.3 & 6.0 & 24.5 & 5.3 & 1.1 & 4.7 & 0.6 & 3.5 & 0.64 & 1.7 & 1.47 & 0.21 & 119 & 1.00 & -10.0 & $-11.3 *$ & \\
\hline 7 & 6.4 & & 25.1 & 58.2 & 7.7 & 31.4 & 6.6 & 1.5 & 5.4 & 0.8 & 4.2 & 0.78 & 2.1 & 1.82 & 0.26 & 146 & 0.96 & -5.8 & -8.7 & \\
\hline 8 & 12.1 & 5.3 & 5.6 & 13.7 & 1.7 & 7.3 & 1.7 & 0.4 & 1.4 & 0.2 & 1.0 & 0.17 & 0.5 & 0.39 & 0.06 & 34 & 1.02 & -10.1 & $-11.9 *$ & \\
\hline 9 & 3.6 & & 26.4 & 46.3 & 7.1 & 28.2 & 6.2 & 1.4 & 6.0 & 0.8 & 4.2 & 0.72 & 1.8 & 1.29 & 0.18 & 131 & 0.78 & -12.2 & -13.3 & \\
\hline 10 & 4.7 & & 11.9 & 32.5 & 3.5 & 13.9 & 3.1 & 0.6 & 3.1 & 0.4 & 2.4 & 0.45 & 1.2 & 0.96 & 0.13 & 74 & 1.15 & -13.7 & -14.1 & \\
\hline 11 & 15.7 & & 8.9 & 22.0 & 2.6 & 10.0 & 1.8 & 0.4 & 1.5 & 0.2 & 1.0 & 0.18 & 0.5 & 0.40 & 0.06 & 50 & 1.05 & -13.2 & $-14.0 * *$ & \\
\hline 12 & 13.0 & & 11.1 & 25.6 & 3.2 & 12.4 & 2.3 & 0.5 & 2.1 & 0.3 & 1.5 & 0.27 & 0.7 & 0.60 & 0.08 & 61 & 0.99 & -9.3 & $-12.0 * *$ & \\
\hline 13 & 5.3 & & 17.5 & 35.8 & 4.5 & 16.3 & 2.8 & 0.6 & 2.2 & 0.3 & 1.6 & 0.28 & 0.8 & 0.67 & 0.08 & 83 & 0.93 & -10.8 & -10.4 & \\
\hline 14 & 4.7 & & 7.5 & 17.3 & 1.8 & 6.8 & 1.0 & 0.2 & 1.0 & 0.1 & 0.4 & 0.09 & 0.2 & 0.16 & 0.02 & 37 & 1.09 & -6.4 & -7.1 & \\
\hline 15 & 6.1 & 0.7 & 18.6 & 38.4 & 5.0 & 19.3 & 4.0 & 0.7 & 3.4 & 0.5 & 3.0 & 0.58 & 1.6 & 1.50 & 0.21 & 97 & 0.92 & -13.9 & $-13.8 *$ & \\
\hline 16 & 24.7 & & 5.5 & 11.5 & 1.5 & 5.7 & 1.0 & 0.2 & 0.9 & 0.1 & 0.7 & 0.14 & 0.4 & 0.34 & 0.05 & 28 & 0.92 & -23.3 & $-23.3 *$ & \\
\hline 17 & 10.3 & 5.1 & 44.0 & 96.1 & 11.8 & 44.0 & 8.2 & 1.4 & 6.6 & 0.9 & 5.3 & 1.02 & 2.9 & 2.69 & 0.36 & 226 & 0.97 & -19.7 & $-18.7 *$ & \\
\hline 18 & 7.3 & & 5.6 & 24.2 & 1.5 & 5.3 & 0.9 & 0.2 & 0.7 & 0.1 & 0.4 & 0.06 & 0.1 & 0.11 & 0.01 & 39 & 1.92 & -8.6 & -7.7 & \\
\hline 19 & 5.8 & & 30.3 & 87.9 & 7.3 & 26.8 & 5.0 & 1.1 & 3.9 & 0.5 & 2.9 & 0.53 & 1.5 & 1.22 & 0.15 & 169 & 1.36 & -27.0 & -28.7 & \\
\hline 20 & 2.1 & & 84.3 & 231 & 21.7 & 81.7 & 14.2 & 2.6 & 11.3 & 1.6 & 9.5 & 1.90 & 5.5 & 5.17 & 0.71 & 473 & 1.24 & -21.6 & -21.2 & \\
\hline 21 & 5.7 & & 22.0 & 62.3 & 6.0 & 22.6 & 4.1 & 0.8 & 3.2 & 0.5 & 2.8 & 0.56 & 1.6 & 1.59 & 0.22 & 128 & 1.25 & -20.5 & -21.0 & \\
\hline 22 & 4.3 & & 23.8 & 55.5 & 6.5 & 25.9 & 5.2 & 1.9 & 4.7 & 0.7 & 3.8 & 0.69 & 1.8 & 1.46 & 0.17 & 132 & 1.03 & 4.0 & 3.8 & \\
\hline 23 & 4.9 & & 21.7 & 47.6 & 5.8 & 23.2 & 4.6 & 1.5 & 4.2 & 0.6 & 3.4 & 0.62 & 1.6 & 1.23 & 0.15 & 116 & 0.98 & 4.0 & 3.9 & \\
\hline 24 & 7.6 & 1.6 & 27.2 & 64.7 & 8.1 & 32.3 & 7.2 & 1.5 & 6.2 & 0.9 & 4.8 & 0.85 & 2.2 & 1.81 & 0.23 & 158 & 1.00 & -12.2 & -12.6 & \\
\hline 25 & 6.9 & & 18.0 & 34.9 & 4.6 & 16.4 & 2.9 & 0.6 & 2.9 & 0.5 & 2.9 & 0.56 & 1.6 & 1.44 & 0.20 & 88 & 0.88 & -17.3 & -17.9 * & \\
\hline Estua & ries $(n=18)$ & & & & & & & & & & & & & & & & & & & \\
\hline 26 & 5.9 & 2.2 & 9.2 & 20.9 & 2.8 & 11.7 & 3.0 & 0.7 & 2.9 & 0.4 & 2.4 & 0.45 & 1.2 & 0.99 & 0.14 & 57 & 0.94 & -9.5 & -12.0 & \\
\hline 27 & 5.1 & 1.2 & 30.3 & 71.8 & 8.7 & 34.4 & 7.9 & 1.5 & 6.7 & 1.0 & 5.0 & 0.82 & 2.0 & 1.61 & 0.23 & 172 & 1.01 & -9.3 & -10.0 & \\
\hline 28 & 7.4 & 0.5 & 25.5 & 57.4 & 7.0 & 26.2 & 4.8 & 0.9 & 3.6 & 0.5 & 2.6 & 0.47 & 1.3 & 1.01 & 0.15 & 132 & 0.99 & -14.5 & -10.4 & \\
\hline 29 & 13.4 & 3.5 & 11.1 & 25.2 & 3.2 & 13.2 & 3.0 & 0.6 & 2.6 & 0.4 & 2.1 & 0.39 & 1.0 & 0.85 & 0.12 & 64 & 0.97 & -9.0 & -15.6 & -8.2 \\
\hline 30 & 15.2 & & 18.8 & 49.7 & 6.4 & 24.3 & 4.1 & 0.7 & 2.8 & 0.4 & 1.6 & 0.26 & 0.6 & 0.51 & 0.07 & 110 & 1.03 & -15.4 & $-14.1 *$ & \\
\hline 31 & 9.1 & 3.8 & 44.0 & 100 & 12.5 & 49.2 & 10.5 & 2.2 & 8.7 & 1.2 & 6.6 & 1.17 & 3.1 & 2.60 & 0.30 & 243 & 0.98 & -6.6 & -9.4 & \\
\hline 32 & 15.1 & 5.7 & 3.1 & 8.4 & 1.2 & 5.5 & 1.7 & 0.4 & 1.9 & 0.3 & 1.6 & 0.29 & 0.8 & 0.63 & 0.07 & 26 & 0.97 & -8.6 & -11.2 & \\
\hline 33 & 8.8 & & 8.9 & 20.6 & 2.6 & 9.6 & 1.6 & 0.3 & 1.3 & 0.2 & 0.9 & 0.16 & 0.4 & 0.37 & 0.05 & 47 & 0.98 & -15.5 & $-14.3 * *$ & \\
\hline 34 & 11.4 & 1.6 & 8.1 & 18.4 & 2.4 & 10.1 & 2.3 & 0.5 & 2.1 & 0.3 & 1.6 & 0.30 & 0.8 & 0.69 & 0.10 & 48 & 0.96 & -8.8 & $-11.8 *$ & \\
\hline 35 & 15.4 & 5.2 & 16.7 & 32.8 & 4.4 & 17.1 & 3.5 & 0.7 & 2.9 & 0.4 & 2.0 & 0.36 & 0.9 & 0.83 & 0.11 & 83 & 0.88 & -9.2 & -11.0 & \\
\hline 36 & 4.7 & & 27.1 & 55.2 & 7.3 & 28.1 & 5.7 & 1.2 & 4.8 & 0.7 & 3.8 & 0.67 & 1.8 & 1.53 & 0.19 & 138 & 0.90 & -12.5 & -13.1 & \\
\hline 37 & 34.8 & & 3.6 & 7.5 & 1.0 & 4.0 & 0.8 & 0.2 & 0.8 & 0.1 & 0.6 & 0.11 & 0.3 & 0.21 & 0.03 & 19 & 0.91 & -3.4 & -6.5 & \\
\hline 38 & 12.0 & 1.4 & 8.9 & 18.8 & 2.4 & 9.8 & 2.0 & 0.4 & 1.7 & 0.2 & 1.3 & 0.24 & 0.7 & 0.54 & 0.08 & 47 & 0.94 & -10.2 & $-12.2 *$ & \\
\hline 39 & 8.5 & 1.9 & 8.1 & 15.6 & 2.4 & 10.1 & 2.4 & 0.6 & 2.4 & 0.3 & 2.0 & 0.38 & 1.1 & 0.95 & 0.15 & 47 & 0.81 & -9.2 & $-9.9 *$ & \\
\hline 40 & 14.1 & 3.3 & 19.3 & 38.6 & 5.2 & 20.3 & 3.8 & 0.7 & 2.9 & 0.4 & 2.0 & 0.37 & 0.9 & 0.78 & 0.11 & 96 & 0.89 & -13.2 & -10.0 & \\
\hline 41 & 16.3 & 6.8 & 17.6 & 39.6 & 5.3 & 21.2 & 4.6 & 0.9 & 3.8 & 0.5 & 3.1 & 0.58 & 1.6 & 1.47 & 0.21 & 101 & 0.94 & -13.6 & $-14.3 *$ & \\
\hline 42 & 9.7 & 2.6 & 11.7 & 26.9 & 3.3 & 13.1 & 2.7 & 0.5 & 2.3 & 0.3 & 1.7 & 0.33 & 0.9 & 0.77 & 0.11 & 65 & 0.99 & -15.9 & $-8.9 *$ & \\
\hline 43 & 4.3 & & 38.4 & 70.3 & 10.1 & 38.6 & 7.5 & 1.6 & 6.5 & 0.9 & 5.0 & 0.88 & 2.3 & 1.75 & 0.24 & 184 & 0.82 & -9.7 & -12.0 & -6.7 \\
\hline Oceat & $n(n=15)$ & & & & & & & & & & & & & & & & & & & \\
\hline 44 & 8.2 & 0.4 & 23.4 & 49.3 & 5.9 & 21.5 & 3.8 & 0.7 & 2.9 & 0.4 & 2.2 & 0.41 & 1.1 & 1.00 & 0.14 & 113 & 0.97 & -22.8 & & \\
\hline 45 & 6.4 & & 45.2 & 208 & 12.2 & 46.4 & 8.8 & 1.7 & 7.2 & 1.0 & 5.0 & 0.89 & 2.3 & 1.84 & 0.22 & 342 & 2.04 & -15.1 & -15.5 & -10.0 \\
\hline 46 & 6.3 & 0.4 & 23.0 & 60.5 & 6.5 & 25.6 & 5.3 & 1.2 & 5.4 & 0.7 & 4.0 & 0.75 & 2.0 & 1.63 & 0.22 & 137 & 1.14 & -11.4 & -12.0 & -10.9 \\
\hline 47 & 5.8 & & 34.2 & 72.2 & 10.1 & 39.2 & 7.9 & 1.5 & 6.8 & 0.9 & 4.8 & 0.86 & 2.3 & 1.75 & 0.22 & 183 & 0.89 & -12.1 & -14.2 & -10.0 \\
\hline 48 & 15.5 & 0.6 & 4.8 & 10.2 & 1.4 & 6.3 & 1.6 & 0.4 & 1.7 & 0.3 & 1.5 & 0.28 & 0.8 & 0.64 & 0.08 & 30 & 0.90 & -6.7 & -11.2 & 4.8 \\
\hline 49 & 8.4 & 1.0 & 20.5 & 46.9 & 5.6 & 22.0 & 4.7 & 1.0 & 4.2 & 0.6 & 3.0 & 0.54 & 1.4 & 1.14 & 0.16 & 112 & $\begin{array}{l}1.01 \\
\text { S }\end{array}$ & -9.2 & -11.7 & -8.7 \\
\hline 50 & 14.5 & 2.9 & 21.2 & 71.4 & 7.2 & 28.5 & 5.8 & 1.2 & 4.4 & 0.6 & 3.1 & 0.55 & 1.4 & 1.27 & 0.18 & 147 & 1.31 & -16.1 & -15.8 & -15.4 \\
\hline 51 & 8.0 & 1.9 & 45.0 & 156 & 14.0 & 55.2 & 6.1 & 0.7 & 2.3 & 0.3 & 1.6 & 0.30 & 0.8 & 0.73 & 0.10 & 284 & $\begin{array}{l}1.42 \\
\text { S }\end{array}$ & -16.1 & -15.6 & -14.7 \\
\hline 52 & 9.1 & & 14.2 & 39.5 & 3.3 & 12.6 & 2.5 & 0.5 & 2.3 & 0.3 & 1.7 & 0.33 & 0.9 & 0.70 & 0.10 & 79 & 1.33 & -3.0 & -2.9 & 0.0 \\
\hline 53 & 8.4 & 1.8 & 5.8 & 14.6 & 2.0 & 8.5 & 2.2 & 0.5 & 2.1 & 0.3 & 2.0 & 0.36 & 1.0 & 0.95 & 0.14 & 41 & 0.97 & -0.2 & -0.1 & -4.0 \\
\hline 54 & 10.6 & 2.5 & 5.4 & 13.9 & 1.7 & 7.3 & 1.9 & 0.4 & 1.7 & 0.3 & 1.7 & 0.30 & 0.8 & 0.85 & 0.13 & 37 & 1.05 & -1.3 & -1.9 & -4.0 \\
\hline 55 & 4.4 & 0.2 & 4.5 & 22.9 & 1.3 & 5.0 & 0.9 & 0.2 & 1.0 & 0.1 & 0.7 & 0.12 & 0.3 & 0.25 & 0.03 & 37 & 2.17 & -5.7 & -9.3 & -5.0 \\
\hline 56 & 19.8 & & 12.9 & 79.7 & 3.8 & 16.0 & 3.8 & 0.9 & 3.8 & 0.6 & 3.4 & 0.64 & 1.7 & 1.47 & 0.20 & 129 & 2.61 & -5.0 & -3.1 & -15.0 \\
\hline 57 & 8.5 & & 2.3 & 8.7 & 0.6 & 2.6 & 0.6 & 0.1 & 0.5 & 0.1 & 0.5 & 0.09 & 0.2 & 0.2 & 0.02 & 16 & 1.71 & -10.1 & -10.7 & -8.0 \\
\hline 58 & 8.3 & & 1.4 & 5.4 & 0.4 & 1.5 & 0.33 & 0.1 & 0.3 & 0.04 & 0.2 & 0.04 & 0.10 & 0.09 & 0.01 & 10 & 1.66 & 3.7 & 3.6 & -7.0 \\
\hline Cold & Seeps $(n=12)$ & & & & & & & & & & & & & & & & & & & \\
\hline & Gulf of Guin & & & & & & & & & & & & & & & & & & & \\
\hline 59 & 7.0 & 1.5 & 43.7 & 136 & 13.2 & 50.5 & 9.7 & 2.0 & 7.6 & 1.0 & 5.3 & 0.95 & 2.4 & 2.0 & 0.27 & 275 & 1.29 & -12.0 & -11.2 & -12.6 \\
\hline 60 & 7.1 & 1.4 & 60.8 & 186 & 18.7 & 72.3 & 13.9 & 2.9 & 11.0 & 1.4 & 7.2 & 1.24 & 3.2 & 2.8 & 0.39 & 383 & 1.26 & -12.9 & -11.2 & -12.6 \\
\hline 61 & 12.3 & 1.4 & 45.4 & 136 & 13.9 & 53.7 & 10.1 & 2.0 & 7.6 & 1.0 & 5.1 & 0.86 & 2.2 & 1.9 & 0.25 & 281 & 1.24 & -13.4 & -12.0 & -12.6 \\
\hline 62 & 11.5 & 2.6 & 57.5 & 89.4 & 8.6 & 34.0 & 6.8 & 1.4 & 5.3 & 0.7 & 3.7 & 0.65 & 1.7 & 1.4 & 0.20 & 182 & 0.91 & -15.7 & -15.6 & -15.4 \\
\hline 63 & 11.7 & 2.9 & 30.8 & 120 & 11.2 & 45.5 & 9.8 & 2.1 & 8.4 & 1.1 & 6.1 & 1.06 & 2.8 & 2.2 & 0.26 & 242 & 1.45 & -15.2 & -16.5 & -15.4 \\
\hline & Mediterranec & ea, Nile & rgins & & & & & & & & & & & & & & & & & \\
\hline 64 & 8.9 & 0.8 & 73.0 & 176 & 21.3 & 85.4 & 17.8 & 4.2 & 16.3 & 2.3 & 12.6 & 2.22 & 5.7 & 4.7 & 0.66 & 423 & 1.02 & -2.2 & -4.1 & -5.3 \\
\hline 65 & 6.1 & 0.9 & 124 & 276 & 33.3 & 133 & 27.4 & 6.4 & 24.5 & 3.4 & 18.7 & 3.38 & 8.6 & 7.1 & 0.99 & 668 & 0.99 & -2.4 & -4.2 & -5.3 \\
\hline 66 & 5.6 & 1.2 & 36.1 & 163 & 10.2 & 40.7 & 8.4 & 1.8 & 6.9 & 1.0 & 5.2 & 0.92 & 2.4 & 2.0 & 0.28 & 279 & 1.95 & -4.1 & -8.1 & -5.3 \\
\hline 67 & 9.9 & 1.4 & 36.3 & 80.6 & 10.5 & 41.6 & 8.6 & 1.9 & 7.5 & 1.0 & 5.3 & 0.96 & 2.5 & 2.1 & 0.29 & 200 & 0.95 & -3.9 & -6.1 & -5.3 \\
\hline 68 & 9.2 & 0.8 & 38.0 & 99.6 & 12.5 & 49.8 & 10.2 & 2.0 & 8.5 & 1.3 & 6.8 & 1.24 & 3.2 & 2.7 & 0.38 & 237 & 1.04 & -0.7 & -3.4 & -9.3 \\
\hline 69 & 13.4 & 0.6 & 21.2 & 55.6 & 7.0 & 28.2 & 5.8 & 1.2 & 5.1 & 0.7 & 4.2 & 0.79 & 2.4 & 1.8 & 0.26 & 135 & 1.04 & -0.8 & -3.4 & -9.3 \\
\hline 70 & 8.0 & 1.3 & 18.1 & 44.9 & 6.1 & 26.3 & 6.1 & 1.4 & 5.7 & 0.8 & 4.3 & 0.80 & 2.2 & 1.8 & 0.27 & 119 & 0.97 & -3.9 & -6.4 & -9.3 \\
\hline
\end{tabular}




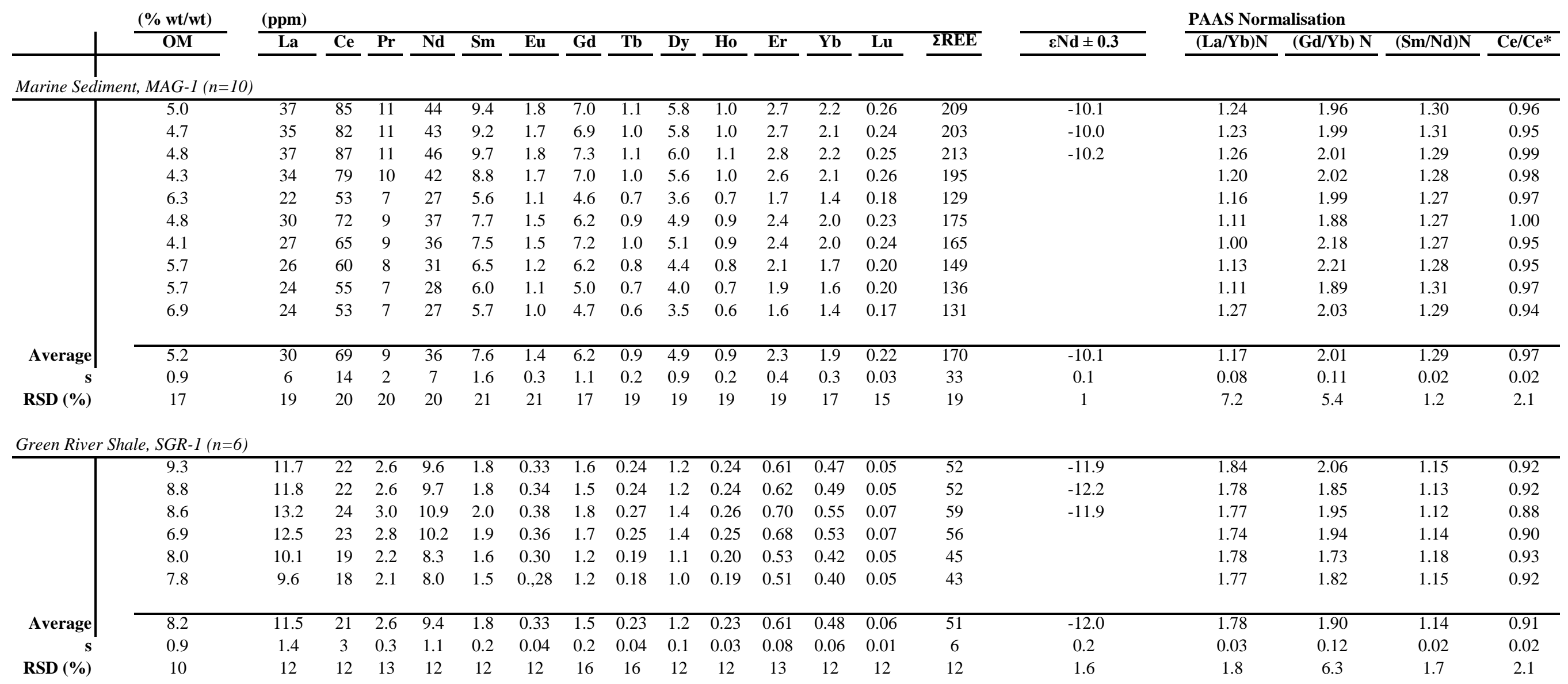




\begin{tabular}{|c|c|c|c|c|c|c|c|c|c|c|c|c|c|c|}
\hline & La & $\mathrm{Ce}$ & $\operatorname{Pr}$ & Nd & Sm & Eu & Gd & Tb & Dy & Ho & Er & $\mathrm{Tm}$ & $\mathbf{Y b}$ & Lu \\
\hline \multicolumn{15}{|c|}{ Seawater (ng.kg-1) } \\
\hline & 4.17 & 0.63 & 0.54 & 2.88 & 0.60 & 0.15 & 0.74 & 0.17 & 1.06 & 0.33 & 1.09 & 0.17 & 1.12 & 0.23 \\
\hline \multicolumn{15}{|c|}{ River water (ng.kg-1) } \\
\hline & 66.3 & 102 & 18.9 & 91.2 & 21.5 & 4.37 & 21.2 & 3.07 & 19.6 & 4.04 & 12.4 & 2.08 & 14.7 & 2.34 \\
\hline \multicolumn{15}{|c|}{ Anoxic Pore water (ng.kg-1) } \\
\hline & 60.0 & 176 & 16.4 & 65.5 & 12.7 & 2.89 & 11.4 & 1.61 & 9.1 & 1.88 & 5.3 & 0.71 & 4.6 & 0.71 \\
\hline \multicolumn{15}{|c|}{ Biogenic carbonates (ng.g-1) } \\
\hline & 130 & 192 & 33.7 & 140 & 34.3 & 11.2 & 48.0 & 8.7 & 58.5 & 16.6 & 49.7 & 6.53 & 41.6 & 7.30 \\
\hline \multicolumn{15}{|c|}{ Fe-Mn oxy-hydroxides (mg.g-1) } \\
\hline & 3.63 & 5.07 & 0.60 & 2.46 & 0.48 & 0.11 & 0.52 & 0.09 & 0.53 & 0.11 & 0.34 & 0.05 & 0.35 & 0.05 \\
\hline \multicolumn{15}{|c|}{ Fe-Mn oxides (mg.g-1) } \\
\hline & 161 & 826 & 36.7 & 152 & 32.7 & 8.06 & 39.2 & 6.20 & 32.9 & 6.12 & 16.6 & 2.53 & 15.4 & 2.22 \\
\hline \multicolumn{15}{|c|}{ Sedimentary Organic Matter (mg.g-1) } \\
\hline & 19.10 & 49.0 & 5.35 & 20.8 & 4.09 & 0.85 & 3.45 & 0.48 & 2.64 & 0.49 & 1.30 & - & 1.11 & 0.15 \\
\hline \multicolumn{15}{|l|}{ PAAS (mg.g-1) } \\
\hline & 38.20 & 79.59 & 8.83 & 33.90 & 5.55 & 1.08 & 4.65 & 0.78 & 4.68 & 0.99 & 2.84 & 0.41 & 2.82 & 0.44 \\
\hline
\end{tabular}




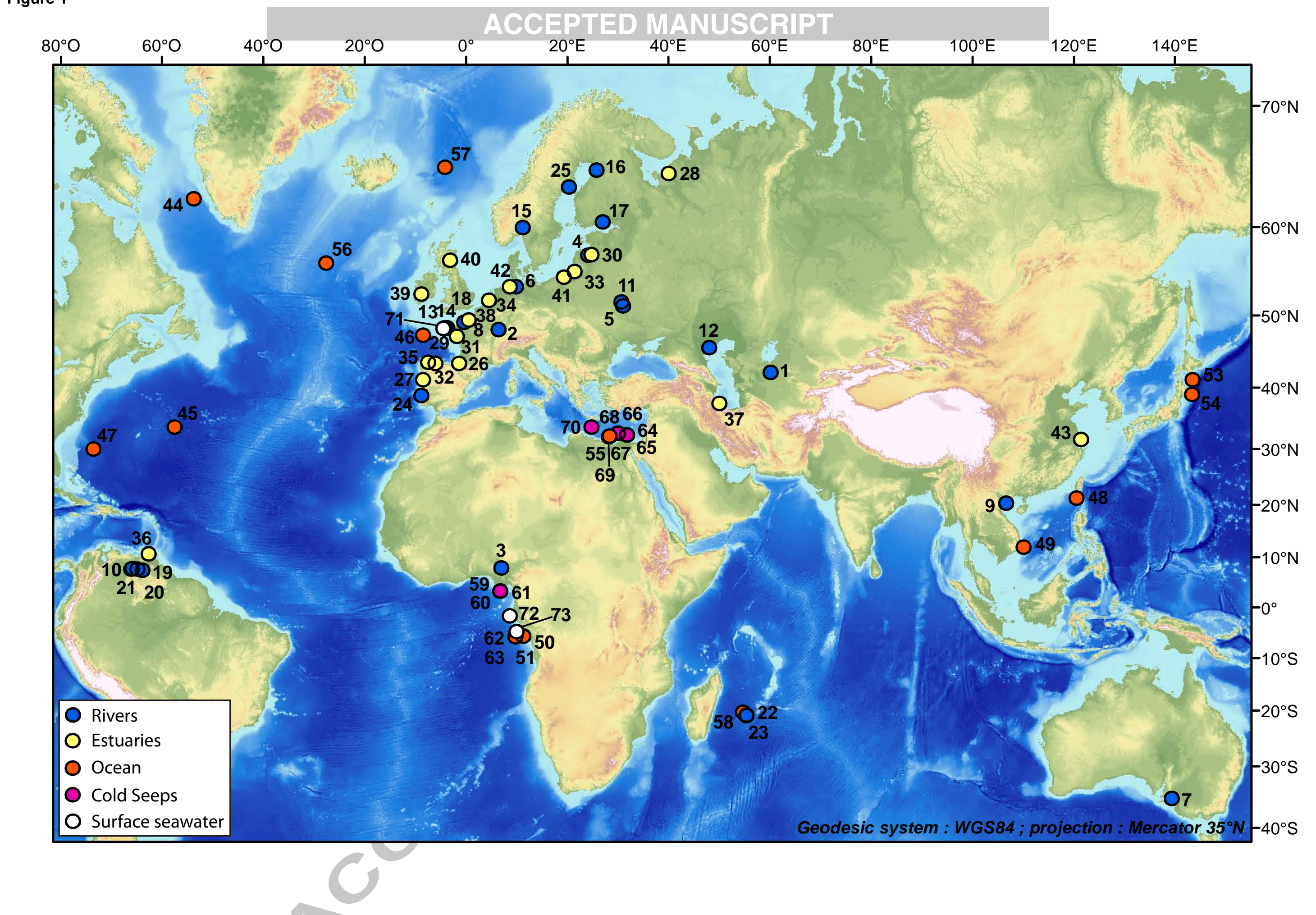




\section{(a) North Atlantic marine sediment}

$\%$ of bulk sediment dissolved

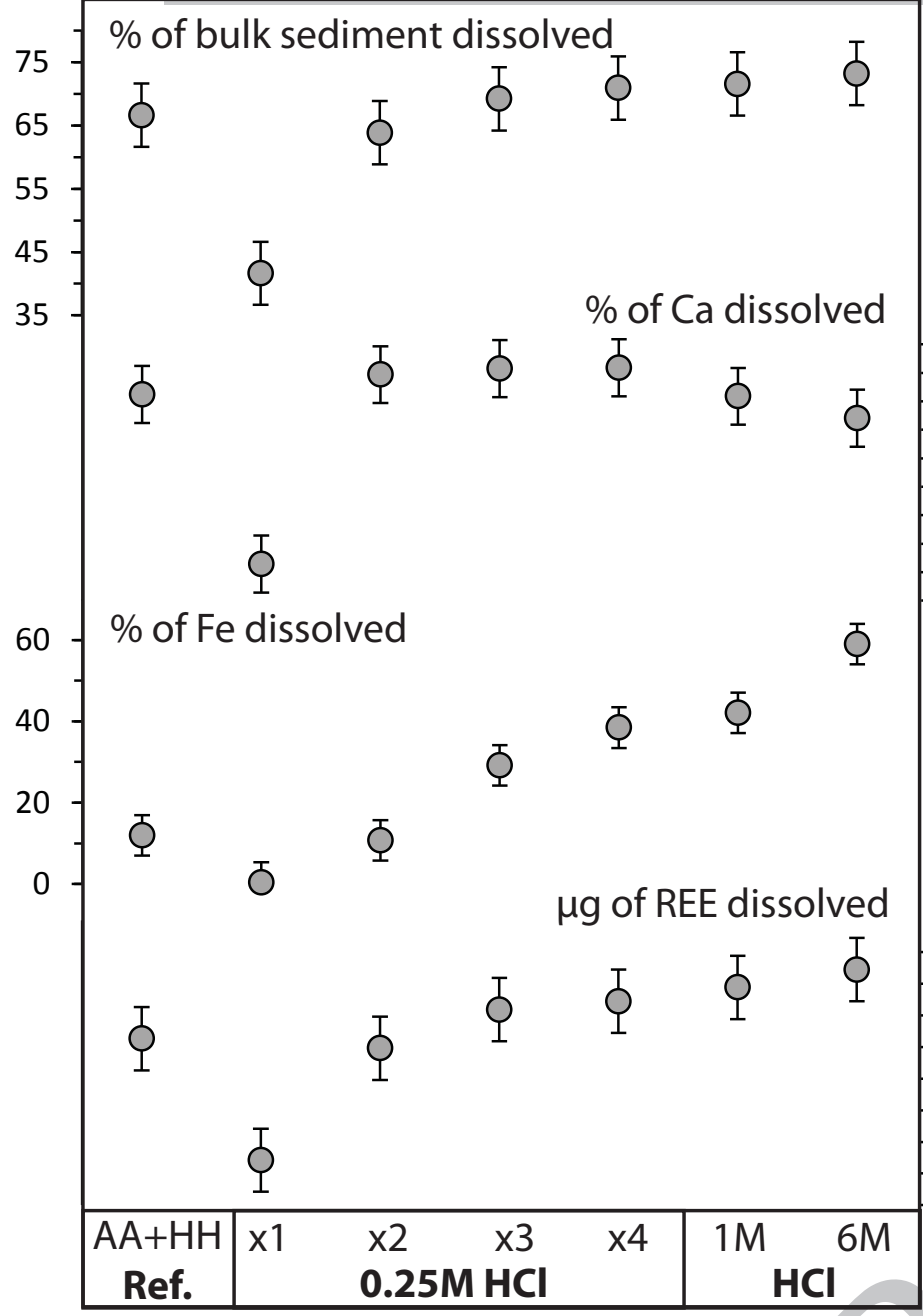

(b) Murray River sediment

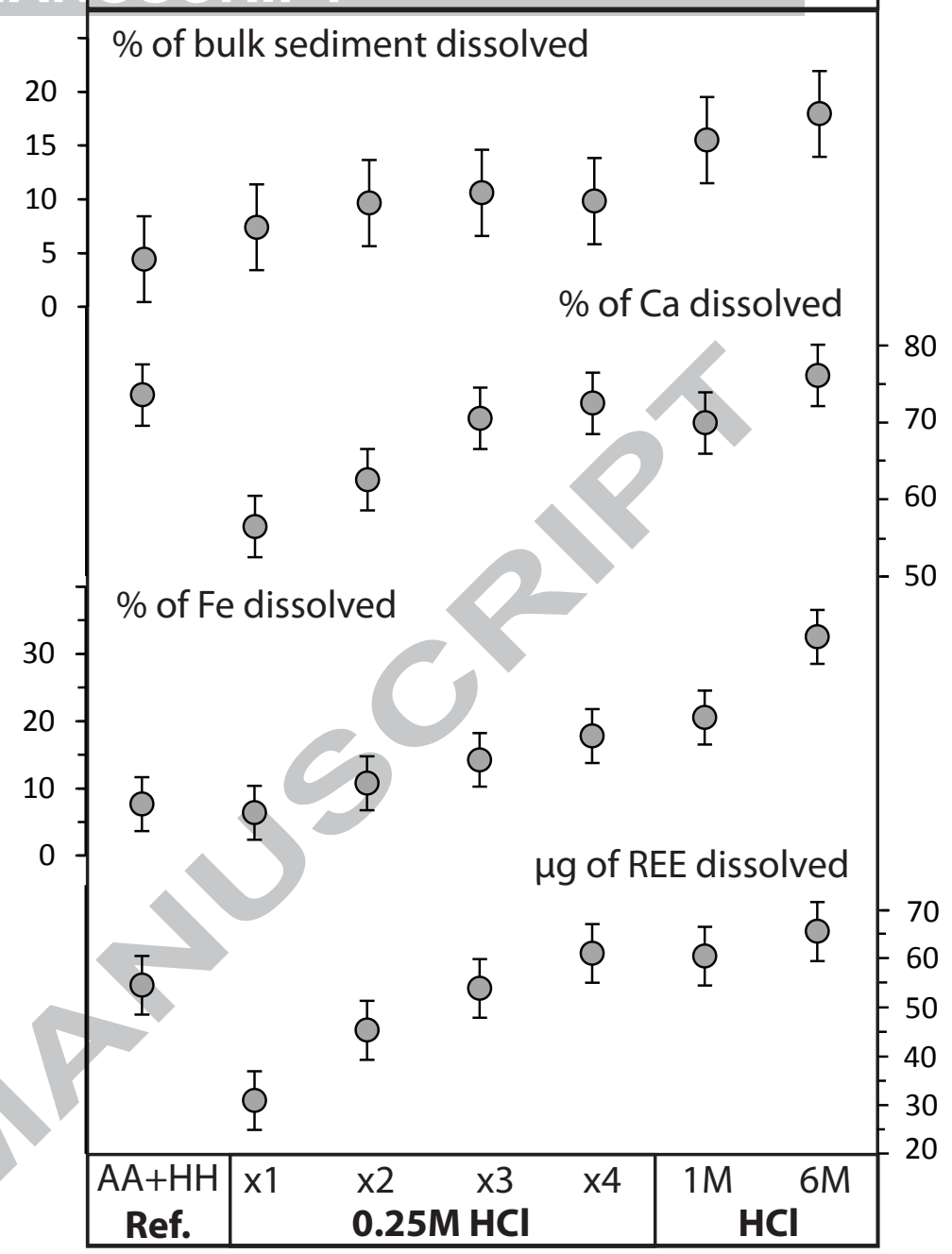

(d) $\quad \mathrm{H}_{2} \mathrm{O}_{2}$ leach Murray River sediment

15

$\%$ of bulk sediment dissolved

$\Phi$

$\mathrm{H}_{2} \mathrm{O}_{2}$ leach -

$\mathrm{N}$ Atlantic marinesediment

$\%$ of bulk sediment dissolved

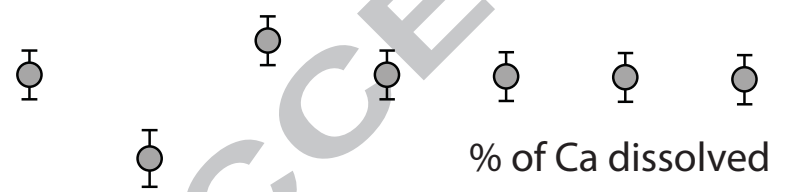

$\delta \quad \delta \quad \delta \quad \delta \quad \delta \quad \delta \underbrace{5}$

$\%$ of Fe dissolved<smiles>[3H]CCCCCCCCC[3H]</smiles><smiles>COCO</smiles>

$5-1$<smiles>COCOCO</smiles>

$\mu \mathrm{g}$ of REE dissolved

$-3$

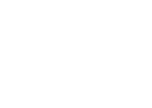

I

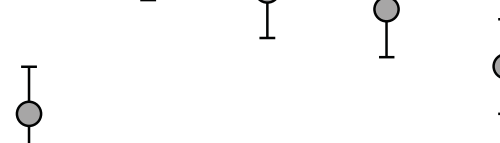

$\mathrm{AA}+\mathrm{HH} \times \mathrm{x}$

Ref.

$0.25 \mathrm{M} \mathrm{HCl}$ $\oint \oint$

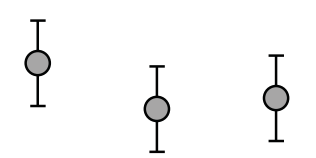

$\%$ of Ca dissolved<smiles>COCCOC</smiles>

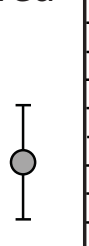

1<smiles>COCOC</smiles>

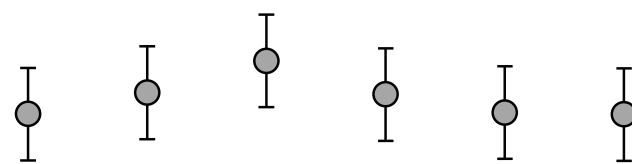

$\mu \mathrm{g}$ of REE dissolved

T

I

$\begin{array}{lllll}1 & 1 & 1 & 1 & -4 \\ 1 & 1 & 1 & 0\end{array}$
$\%$ of Fe dissolved

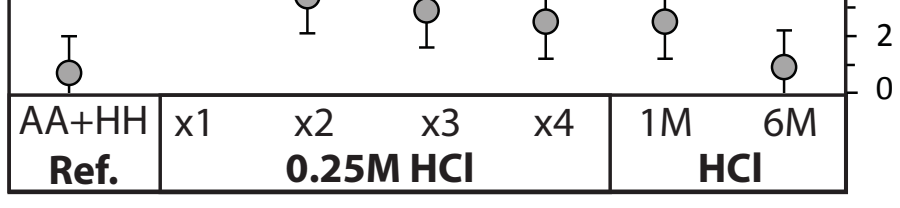




\section{Figure 3}
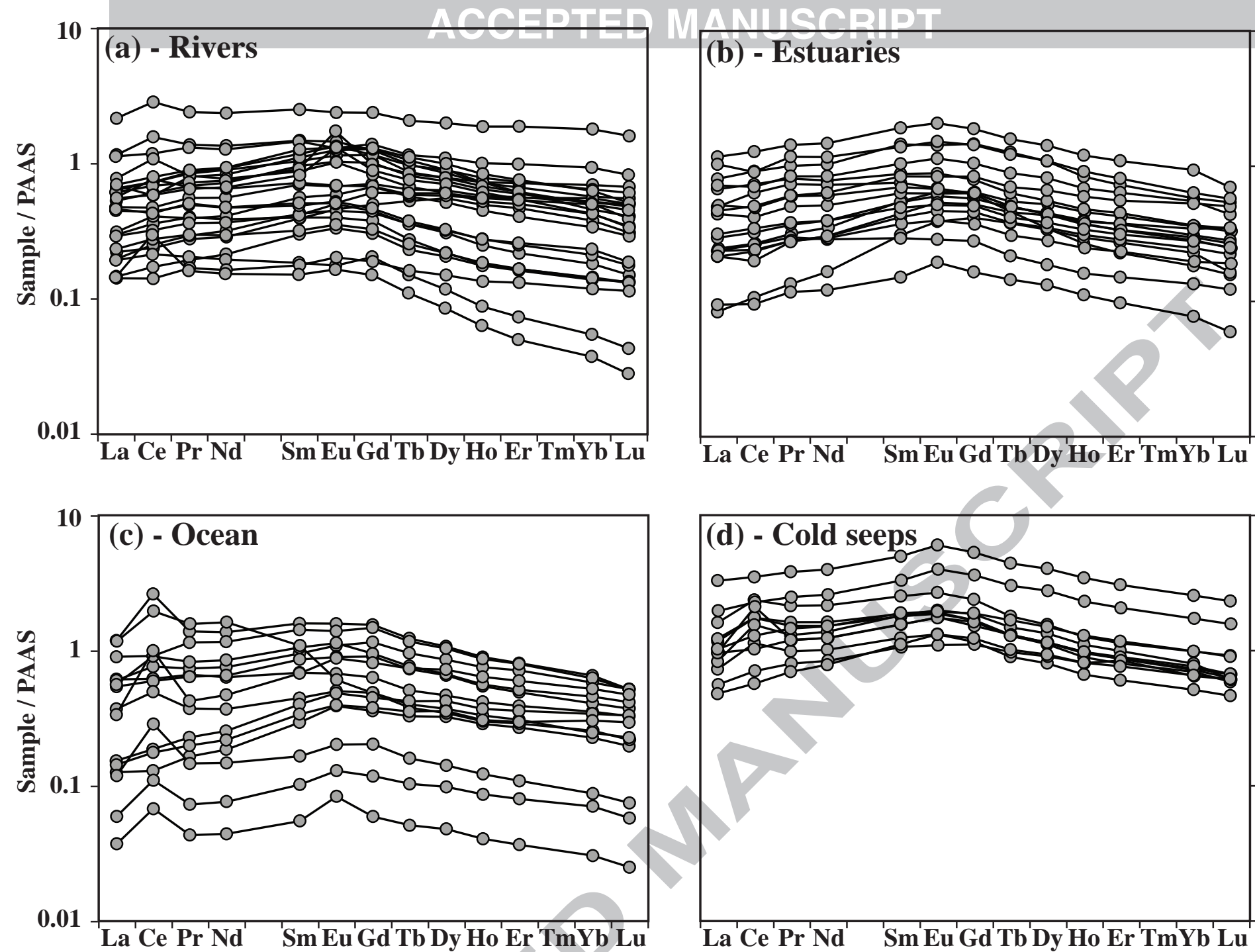

10

0.1 峞

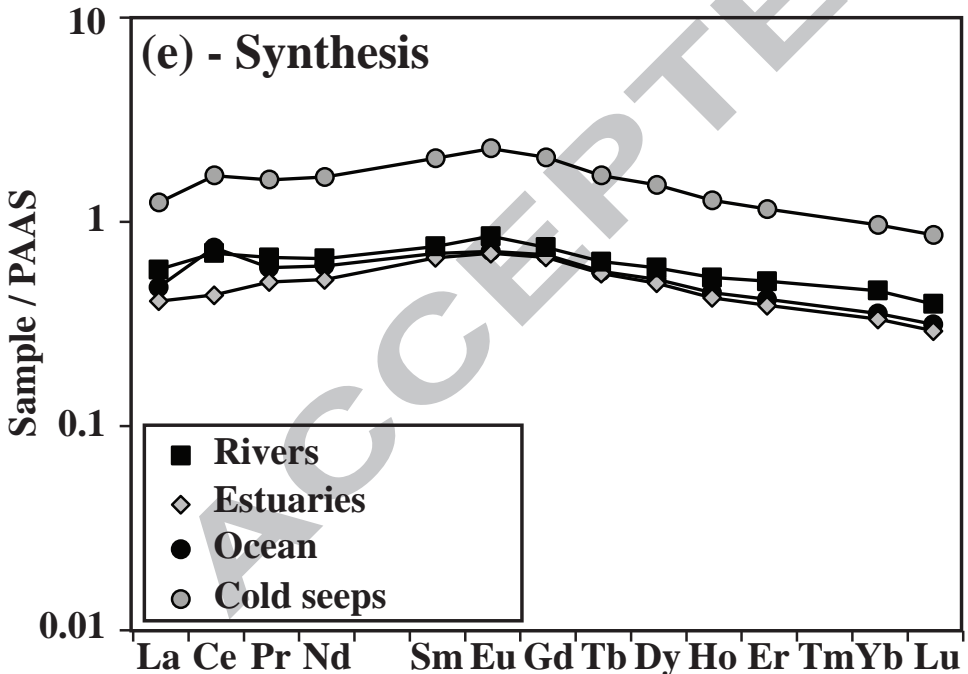


Figure 4

$\varepsilon \mathrm{Nd}_{\mathrm{OM}}$

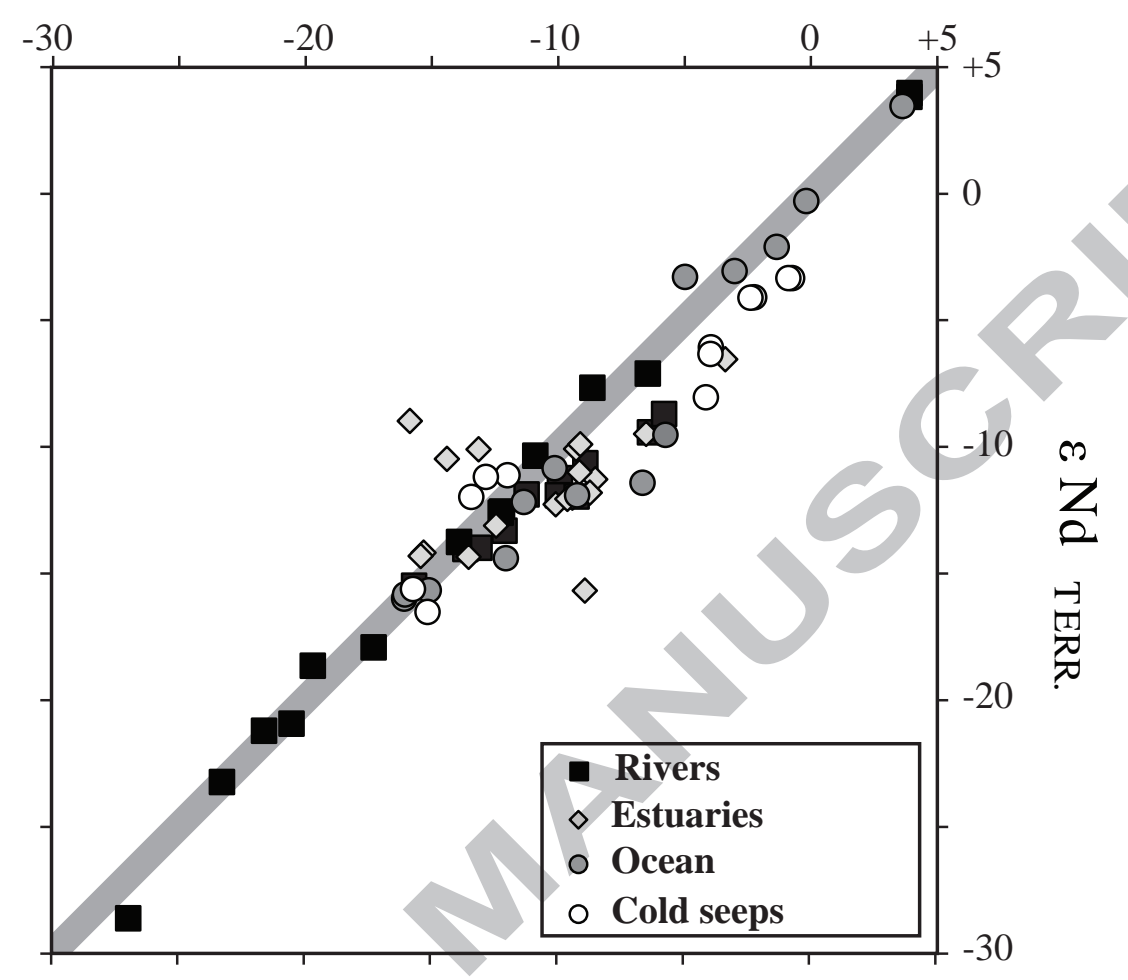


ACCEPTED MANUSCRIPT

ENd
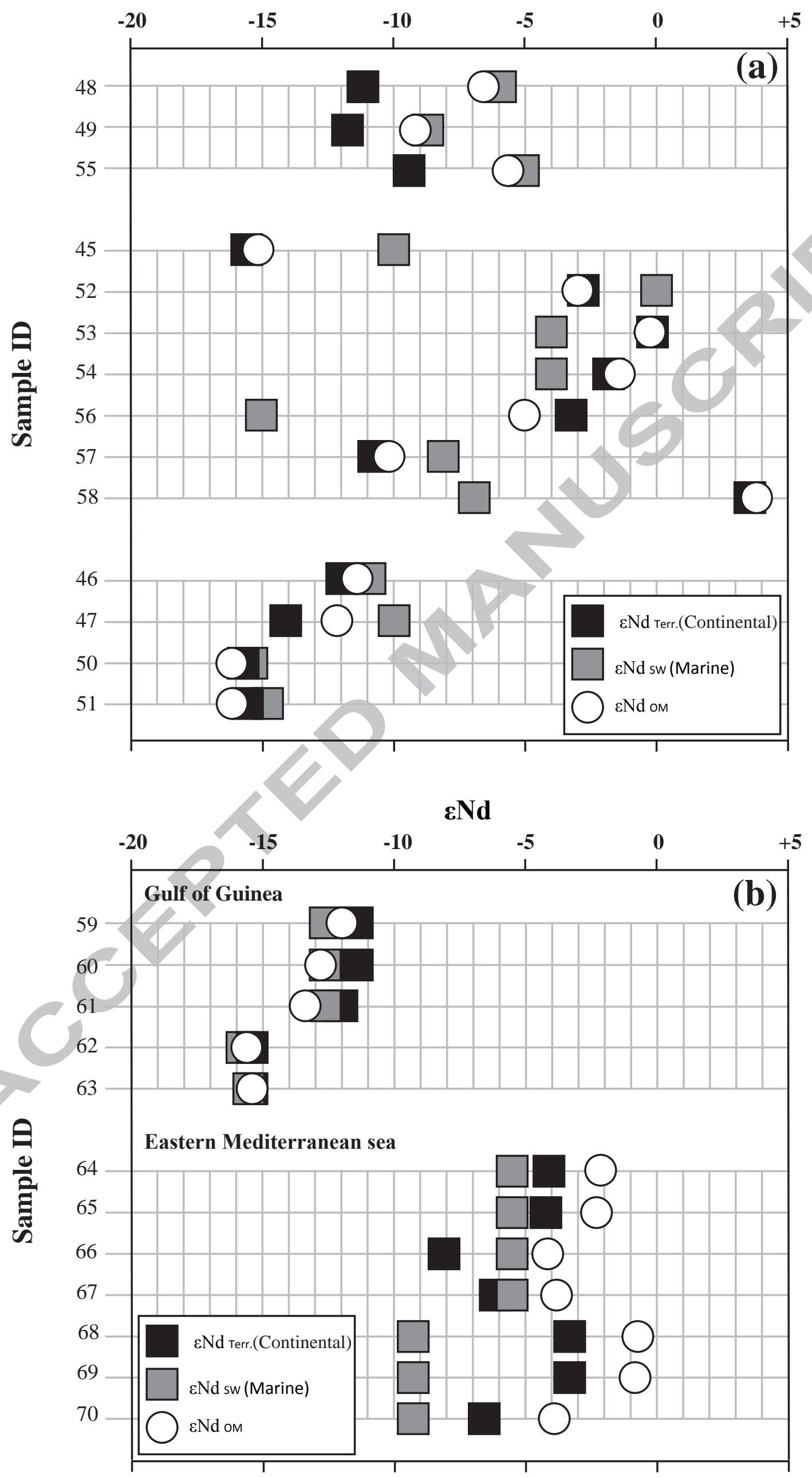

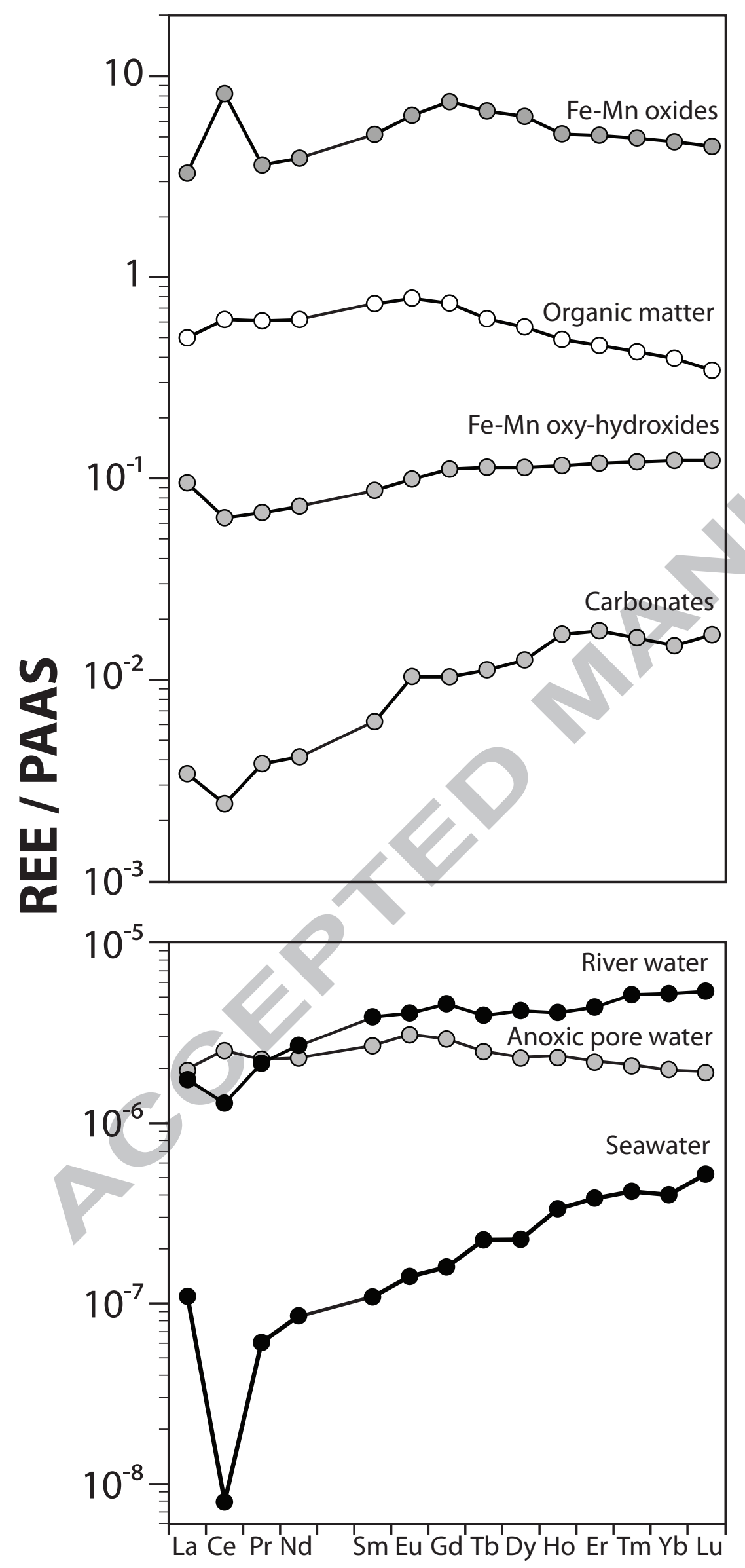